\title{
Dynamic return and volatility connectedness for dominant agricultural commodity markets during the COVID-19 pandemic era
}

\section{Zaghum Umar}

Zayed University https://orcid.org/0000-0002-0425-2665

Francisco Jareño ( $\square$ francisco.jareno@uclm.es )

University of Castilla-La Mancha https://orcid.org/0000-0001-9778-7345

Ana M. Escribano

University of Castilla-La Mancha https://orcid.org/0000-0003-1416-3401

\section{Research Article}

Keywords: Agricultural commodity markets, Coronavirus Media Coverage Index (MCl), Connectedness, COVID-19 pandemic crisis

Posted Date: September 11th, 2020

DOI: https://doi.org/10.21203/rs.3.rs-75766/v1

License: (c) (i) This work is licensed under a Creative Commons Attribution 4.0 International License. Read Full License

Version of Record: A version of this preprint was published at Applied Economics on September 5th, 2021. See the published version at https://doi.org/10.1080/00036846.2021.1973949. 


\title{
Dynamic return and volatility connectedness for dominant agricultural commodity markets during the COVID-19 pandemic era
}

\author{
Zaghum Umar \\ College of Business, Zayed University, United Arab Emirates \\ Francisco Jareño (corresponding author) \\ Faculty of Economic and Business Sciences, University of Castilla-La Mancha, Albacete (Spain). \\ Email: Francisco.Jareno@uclm.es \\ Ana M. Escribano \\ Faculty of Economic and Business Sciences, University of Castilla-La Mancha, Albacete (Spain).
}

\begin{abstract}
This paper explores the dynamic return and volatility connectedness for the three most relevant agricultural commodity markets (Soft, Grain and Livestock) and the Coronavirus Media Coverage Index (MCI) extracted from RavenPack. In concrete, we apply the fresh TVP-VAR methodology proposed by Antonakakis and Gabauer (2017) during the sample period between January 22, 2020 and July 31, 2020, that is in the context of the COVID-19 pandemic crisis. Interesting results are found in this research. First, dynamic total return and volatility connectedness fluctuates over time, reaching a peak during the heart of the global pandemic crisis, initially in the dynamic total return connectedness and later in the volatility one. Second, in the dynamic connectedness TO the system, we observe significant differences between the agricultural commodity markets in the level of the return connectedness measure. However, in the dynamic volatility connectedness TO, there are very few differences between some elements of the system, highlighting the Coronavirus MCI as one of the major transmitters TO the system at some points in the sample. This Coronavirus MCI appears as the less relevant receiver FROM the system, not only in terms of dynamic return connectedness, but also in volatility. Finally, regarding the net dynamic total connectedness, the Coronavirus MCI shows the highest values in return and volatility. Next, in order of highest to lowest net dynamic return and volatility connectedness we find the Grain commodity market, then the Soft market and finally the Livestock market. This last commodity market shows a negative net dynamic connectedness throughout the entire sample period analysed, exhibiting negative peaks in return at the beginning of the pandemic's epicentre and in volatility in the middle of the COVID-19 crisis.
\end{abstract}

Keywords: Agricultural commodity markets; Coronavirus Media Coverage Index (MCI); Connectedness; COVID-19 pandemic crisis

JEL classification: C22, C51, Q02, Q14 


\section{Introduction}

Agricultural commodities are crucial resources to the social stability and food security of many countries, particularly to the progress of developing countries. Policy makers try to design policies that attempt to control sharp price variations. In addition, agricultural commodities are strategical assets for managers and investors in their asset allocation, hedging, or risk management strategies. Hence, it is of interest monitoring, controlling and understanding the price evolution of these commodity markets.

The emergence of the pandemic caused by the SARS-CoV-2 Coronavirus, identified as COVID-19 disease by the World Health Organization (WHO) on February 11, 2020, has affected commodity markets. Goodell (2020) defines the COVID-19 pandemic as an unprecedented episode of global crisis with a destructive economic damage never seen before. Therefore, this period of economic and social turbulence, comparable to the Global Financial Crisis caused by subprime mortgages in 2007-2008, emerges as a critical period of time, and so much research has focused on studying the effect of this COVID19 pandemic crisis on several financial markets such as commodity markets (e.g., Bakas and Triantafyllou, 2020; Salisu et al., 2020a; Salisu et al., 2020b; Corbet et al., 2020; Conlon and McGee, 2020; Wang et al, 2020, among others). In concrete, this study tries to fill the gap in recent research by examining the impact of the SARS-CoV-2 coronavirus crisis on the most relevant agricultural commodity markets, that is Grain, Soft and Livestock.

\section{[INSERT FIGURE 1 ABOUT HERE]}

If we observe the evolution of the spot prices of the agricultural commodity indexes from Datastream between January 22, 2020 to July 31, 2020 (period that includes the global pandemic crisis) collected in Figure 1, we detect a fall in the spot prices shown, fundamentally in the epicenter of the crisis, between the end of February and the beginning of May, and mainly for the Livestock market. This evolution would show the impact of the crisis on the agricultural commodity markets and the interest in carrying out this research.

Thus, the main aim of this study is to examine different dynamic return and volatility connectedness measures of the selected agricultural commodity markets (Grain, Soft and Livestock), considering the public sentiment as measured by the Media Coverage Index (MCI). According to Cepoi (2020), we include in our analysis the Coronavirus MCI 
extracted from RavenPack in order to study the influence of the amount of SARS-CoV-2 coronavirus news in comparison with another sort of news pandemic on the dominant agricultural commodity markets.

In particular, we investigate the dynamic connectedness between the media related sentiment and the industrial metals by applying the recent TVP-VAR methodology, focusing on the COVID-19 pandemic crisis (from January 22, 2020 to July 23, 2020). This fresh approach proposed by Antonakakis and Gabauer (2017), and used in Gabauer and Gupta (2018), and in Antonakakis et al. (2020), among others, lets us to classify the selected agricultural commodity markets into net transmitters TO and net receivers FROM the system. As suggested by Antonakakis and Gabauer (2017), the TVP-VAR methodology tolerates us to the overcome the disadvantages of the rolling window connectedness approach proposed by Diebold and Yilmaz (2012) in case of relative short time series data, such as the coronavirus pandemic crisis period analysed in this research. To our best knowledge, the most relevant contributions of this paper are twofold. First, this research explores different dynamic return and volatility connectedness measures selecting the dominant agricultural commodity markets (Grain, Soft and Livestock) and applying for the first time the TVP-VAR methodology. Second, we propose the application of the Coronavirus MCI in order to study the influence of the COVID-19 pandemic crisis on these agricultural commodity markets. Thus, combining both two contributions, we can differentiate which commodity markets are net transmitters and which net receivers between the Grain, Soft and Livestock commodity markets.

Our most relevant and interesting results are the following. First, the dynamic total return and volatility connectedness measures changes over time. In addition, these measures get a peak in the epicentre of the SARS-CoV-2 pandemic crunch, showing first the effect in terms of return and later in volatility. Second, in the dynamic connectedness TO the system, we observe significant differences in the level of the return connectedness reached by each agricultural commodity market, but not in the volatility one. The Coronavirus MCI would be the major transmitter TO the system and, at the same time, the less relevant receiver FROM the system, so the Coronavirus MCI reveals the highest values in the net dynamic return and volatility connectedness measures. Regarding the agricultural commodity markets, the Grain market shows the highest net dynamic connectedness, followed by the Soft market and the Livestock commodity market. Moreover, the latter market would be the most affected commodity market during the 
global coronavirus pandemic crisis. By considering the relevance of the agricultural commodity markets studied in this paper, it would be necessary to implement crucial policy measures aimed at assuring price stability throughout periods of economic turmoil.

The rest of the paper is organised as follows. Section 2 provides a literature review on the dynamic connectedness in agricultural commodity markets and the influence of the COVID-19 pandemic crisis. Section 3 describes the TVP-VAR methodology proposed by Antonakakis and Gabauer (2017). Section 4 presents the data. Section 5 offers detailed information about the empirical results. Finally, Section 6 reports the main concluding remarks.

\section{Literature review}

In this section we set the context in which our study is framed by reviewing the prior standing literature related with the aim of this paper. There is a vast literature on the pricing, connectedness, and volatility spillovers on commodity markets. The majority of the studies that include agricultural and livestock commodities, focuses on examining the linkages between returns or volatilities of these commodities, and return or volatility of crude oil or energy prices (e.g., Kaltalioglu and Soyas, 2011; Serra, 2011; Du and McPhail, 2012; Reboredo, 2012; Nazlioglu et al., 2013; Koirala et al., 2015; Cabrera and Schulz, 2016; Kang et al., 2017; Zhang and Broadstock, 2018; Yahya et al., 2019; Dahl et al., 2019; Tiwari et al., 2020; Yip et al., 2020). The evidence found is mixed, and several studies document significant relationship between oil and agricultural commodities while so many others have shown the opposite. For instance, Du and McPhail (2012) study volatility spillovers between crude oil and agricultural commodities and find a significant degree of volatility transmission. Similar results can be found in Koirala et al. (2015), who examine the linkages between energy and the agricultural commodities of corn and soybean. Kang et al. (2017) investigate the dynamics of return and volatility spillover indices of six commodity futures markets, finding evidence of positive equicorrelation between commodity futures market returns, and of bidirectional return and volatility spillovers across commodity futures markets. Recently, Dahl et al. (2019) analyze whether there exist spillover effects among crude oil and agricultural commodities markets and find, among other results, that there exist an asymmetric and bidirectional flow of information between crude oil and agricultural commodities, and that such relationship intensifies during turmoil periods. Contrary, Kaltalioglu and Soyas (2011) find insignificant relationship between oil and agricultural commodities and food 
items. Cabrera and Schulz (2016) examine the linkages between energy and agricultural markets finding no evidence of the energy as the source causing the increasing volatility in agricultural prices. In addition, there are several studies on the connectedness between agricultural commodities, and stock markets (e.g., Chevallier and Ielpo, 2013; Creti et al., 2013; Delatte and López, 2013; Mensi et al., 2013; Silvennoinen and Thorp, 2013; Mensi et al., 2015; Nagayev et al., 2016; Aït-Youcef, 2018). Again, it should be noted that there is also a lack of consensus about the evidence found related to the relationship among stock and commodity markets.

Importantly, Agricultural and Livestock are crucial sectors of the economy, particularly during recession periods. In this line, there is a strand of the literature that empirically investigates whether counter-cyclical movements in commodity markets can be explained by the uncertainty that arises around episodes of global distress (e.g., Schewert, 1989; Hamilton and Lin, 1996; Ludvigson and Ng, 2009; Paye, 2012, Engle et al., 2013; Gargano and Timmermann, 2014). More recently, Bakas and Triantafyllou (2018) studies the impact of macroeconomic events on the volatility of agricultural, metals and energy commodities, and find that there is a positive effect on volatility derived from such kind of shocks. In the same line, Prokopczuk et al. (2019) analyze the relationship between economic uncertainty and main commodity markets of agricultural, livestock, energy, and metals. They find there is a strong link between economic and financial uncertainty and commodity market volatility.

Apart from the empirical evidence on the effects of economic uncertainty on commodity markets, there is an increasing and recent literature about the effects of the COVID-19 crisis on a wide set of different markets and frameworks. The recent COVID19 pandemic crisis provides researchers with a new scenario of global distress in which empirically analyze its impact. This crisis has led to the emergence of several recent studies that explores how this economic worldwide crisis has impacted on different commodity markets. ${ }^{1}$ For instance, Bakas and Triantafyllou (2020) study the effects of the coronavirus pandemic on commodity prices' volatility, but they focus on a general commodity index as well as two sub-indices of crude and gold. They find that the oil market responds significatively negative to the uncertainty related with the pandemic,

\footnotetext{
1 The COVID-19 pandemic crisis declared by the World Health Organization (WHO) on March 11, 2020, represents the major episode of worldwide turmoil since the Global Financial Crisis of 2007-2008. Goodell (2020) defines the COVID-19 pandemic as an unprecedented episode of global crisis with a destructive economic damage never seen before.
} 
whereas the effect in the gold market is positive but less significant. Other authors as Salisu et al. (2020a) find evidence of the positive relationship between commodity returns and COVID-19 fear. Besides, Salisu et al. (2020b) provide some preliminary results about the impact of the COVID-19 crisis on both oil and stock markets. Similarly, Sharif et al. (2020) analyze the connectedness between the coronavirus spread and the oil and stock markets. Other authors as Corbet et al. (2020) examine potential contagion effects of the COVID-19 pandemic on gold and also on cryptocurrencies. In the same line, the study of Conlon and McGee (2020) try to find out whether cryptocurrencies are acting as safe haven assets given the volatility in the equity markets. Wang et al. (2020) examine the effects derived from the pandemic on the cross-correlations between crude oil and agricultural futures markets. They find strong correlation between oil and sugar, and such linkage become stronger under the period of COVID-19 crisis.

More recently, the potential effect and influence of media reporting on investor's sentiment has received more academic attention (e.g., Tetlock, 2007; Tetlock et al., 2008), since information surrounding relevant news could play an important role on investor's investment decisions (Groß-Klußmann and Hautsch, 2011; Renault, 2017). One of the firsts studies in this topic is that of Barberis et al. (1998), who show that financial markets overreact to media news even when such news are not relevant enough. To explain the effects observed on financial markets, the literature has used different mood proxies to measure investor's sentiment, namely, proxies from surveys, market data of traditional media content (Renault, 2017). The researches of Tetlock (2007), Kaplanski and Levy (2010), and Su et al. (2017), among others, rely on proxies from media reporting to analyze the effects observed on market behavior. In the particular context of the COVID19 outbreak, a proxy based on media content has arisen. It is the Coronavirus Media Coverage Index (MCI), which measures the quantity of coronavirus-related news compared to other kind of news. The index is a good indicator of the percentage of sources that cover the coronavirus news among all news sources, and has been used in Cepoi (2020) and Haroon and Rizvi (2020) to analyze the effects of the sentiment generated by COVID-19 news on the markets. Cepoi (2020) studies the relationship between COVI19 related news and the stock markets of six of the most affected countries by the pandemic. They find evidence of a negative link between the number of news related with the COVID-19 and the stock returns. Haroon and Rizvi (2020) focus on volatility of 
equity markets and find that the panic generated by the media is positively associated with the increase in the stock market volatility.

The methodological approach used in the prior literature to study the effects on commodity markets is wide, including methods as GARCH models ( $\mathrm{Du}$ and McPhail, 2012; Creti et a., 2013; Silvennoinen and Thorp, 2013; Cabrera et al., 2016; Nagayev et al., 2016; Kang et al., 2017; Corbet et al., 2020), copulas (Delatte and López, 2013; Koirala et al., 2015), regression analysis (Salisu et al., 2020a), VAR models (Bakas and Triantafyllou, 2020; Salisu et al., 2020b), and causality and wavelet analysis (Sharif et al., 2020). In this research we empirically adopt the novel time-varying parameter vector autoregression (TVP-VAR) methodology developed by Antonakakis and Gabauer (2017) as an extension and an improvement of the Diebold and Yilmaz (2009, 2012, 2014) connectedness approach. We apply this methodology to analyse return and volatility spillovers between shocks derived from the SARS-CoV-2 crisis, measured by the coronavirus MCI, and three main agricultural commodity markets, Grains, Softs and Livestock. This methodology has been also used in Gabauer and Gupta (2018) and in Antonakakis et al. (2020). Gabauer and Gupta (2018) study the economic policy uncertainty spillovers between the US and Japan and find that monetary policy uncertainty is the main driver. Antonakakis et al. (2020) examine dynamic connectedness measures of the four most traded foreign exchange rates against the US dollar. Their results show that the EUR and the CHF are the main transmitters of shocks, whereas the GBP and the JPY are mainly receivers of shocks. In this context, one of the main contributions of this study is to apply the fresh TVP-VAR approach to study the dominant agricultural commodity markets during the heart of the COVID-19 global pandemic crisis.

\section{Methodology}

The approach of network connectedness comes from the methodological innovation proposed by Diebold and Yilmaz $(2009,2012,2014)$. They employ network perspectives jointly with dynamic econometric models in different economic frameworks. Although this methodology has been widely used in the prior standing literature, Antonakakis and Gabauer (2017) proposed and extension and an improvement of the method of Diebold and Yilmaz $(2009,2012,2014)$ through a time-varying parameter vector autoregression (TVP-VAR) methodology. 


\subsection{TVP-VAR methodology}

Diebold and Yilmaz $(2009,2012,2014)$ developed different versions of connectedness procedures, all of them based on the forecast error variance decomposition from vector autoregressions (VAR). The vector autoregression (VAR) method introduced by Sims (1980) solve the problem of the specification of the theoretical reduced form of an underlying system of dynamic simultaneous equations. These equations describe a vector of endogenous variables as linear functions of their own values and each other's past values. However, VAR-based measures in the Diebold and Yilmaz (2009, 2012, 2014) methodology requires to arbitrarily set the rolling window size of the VAR, making the connectedness measures very sensible to the selected size. ${ }^{2}$

Antonakakis and Gabauer (2017) extends the Diebold and Yilmaz (2009, 2012, 2014) method by proposing a time-varying parameter vector autoregression (TVP-VAR) measure that adjust immediately to events avoiding the need to set the rolling window size. The TVP-VAR methodology allows the variance-covariance matrix to vary via a Kalman filter estimation with forgetting factors, which allows to capture possible changes in the underlying structure of the data. In particular, the TVP-VAR model can be written as follows:

$$
\begin{array}{cl}
\boldsymbol{Y}_{t}=\boldsymbol{\beta}_{t} \boldsymbol{Y}_{t-1}+\boldsymbol{\epsilon}_{t} & \boldsymbol{\epsilon}_{t} \mid \boldsymbol{F}_{t-1} \sim N\left(\mathbf{0}, \boldsymbol{S}_{t}\right) \\
\boldsymbol{\beta}_{t}=\boldsymbol{\beta}_{t-1}+\boldsymbol{v}_{t} & \boldsymbol{v}_{t} \mid \boldsymbol{F}_{t-1} \sim N\left(\mathbf{0}, \boldsymbol{R}_{t}\right)
\end{array}
$$

where $\boldsymbol{Y}_{t}$ and $\boldsymbol{Y}_{t-1}$ represent an $N \times 1$ and an $N p \times 1$ dimensional vectors, respectively, $\boldsymbol{\beta}_{t}$ is an $N \times N p$ dimensional time-varying coefficient matrix and $\boldsymbol{\epsilon}_{t}$ is an $N \times 1$ dimensional error disturbance vector with an $N \times N$ time-varying variance-covariance matrix, $\boldsymbol{S}_{t}$. The parameters $\boldsymbol{\beta}_{t}$ depend on their own values $\boldsymbol{\beta}_{t-1}$ and on an $N \times N p$ dimensional error matrix, $\boldsymbol{v}_{t}$, with and $N p \times N p$ variance-covariance matrix, $\boldsymbol{R}_{t}$.

The time-varying coefficients obtained from the TVP-VAR model are complicated to interpret in a standard way, i.e., attending to their values alone. Instead, two general methods are used to interpret the coefficients: the generalised impulse response functions (GIRF) and the generalised forecast error variance decompositions (GFEVD) (Koop et al., 1996; Pesaran and Shin, 1998). Firstly, in order to calculate the

\footnotetext{
${ }^{2}$ A small size of the rolling window could involve an overreaction of the connectedness measure, while a large size could lead to smooth the effects.
} 
GIRF and the GFEVD, the VAR is transformed to its vector moving average (VMA) representation following Antonakakis and Gabauer (2017) as follows:

$$
\begin{aligned}
& \boldsymbol{Y}_{t}=\boldsymbol{\beta}_{t} \boldsymbol{Y}_{t-1}+\boldsymbol{\epsilon}_{t} \\
& \boldsymbol{Y}_{t}=\boldsymbol{A}_{t} \boldsymbol{\epsilon}_{t} \\
& \boldsymbol{A}_{0, t}=\boldsymbol{I} \\
& \boldsymbol{A}_{i, t}=\boldsymbol{\beta}_{1, t} \boldsymbol{A}_{i-1, t}+\cdots+\boldsymbol{\beta}_{p, t} \boldsymbol{A}_{i-p, t}
\end{aligned}
$$

where $\boldsymbol{\beta}_{t}=\left[\boldsymbol{\beta}_{1, t}, \boldsymbol{\beta}_{2, t}, \ldots, \boldsymbol{\beta}_{p, t}\right]^{\prime}, \boldsymbol{A}_{t}=\left[\boldsymbol{A}_{1, t}, \boldsymbol{A}_{2, t}, \ldots, \boldsymbol{A}_{p, t}\right]^{\prime}, \boldsymbol{\beta}_{i, t}$ and $\boldsymbol{A}_{i, t}$ are $N \times N$ dimensional parameter matrices.

The GIRFs measures the responses of all the variables in the system due to a shock in one variable, $i$. In the absence of a structural model, the differences are computed through a $J$-step-ahead forecast, once where variable $i$ is shocked and once where variable $i$ is not shocked. Hence, the difference can be accounted to the shock in variable $i$, which can be calculated as follows:

$$
\begin{aligned}
& \operatorname{GIRF}_{t}\left(J, \boldsymbol{\delta}_{j, t}, \boldsymbol{F}_{t-1}\right)=E\left(\boldsymbol{Y}_{t+J} \mid \boldsymbol{\epsilon}_{j, t}=\boldsymbol{\delta}_{j, t}, \boldsymbol{F}_{t-1}\right)-E\left(\boldsymbol{Y}_{t+J} \mid \boldsymbol{F}_{t-1}\right) \\
& \boldsymbol{\psi}_{j, t}^{g}(J)=\frac{\boldsymbol{A}_{J, t} \boldsymbol{S}_{t} \boldsymbol{\epsilon}_{j, t}}{\sqrt{S_{j j, t}}} \frac{\boldsymbol{\delta}_{j, t}}{\sqrt{S_{j j, t}}} \quad \boldsymbol{\delta}_{j, t}=\sqrt{S_{j j, t}} \\
& \boldsymbol{\psi}_{j, t}^{g}(J)=S_{j j, t}^{-1 / 2} \boldsymbol{A}_{j, t} \boldsymbol{S}_{t} \boldsymbol{\epsilon}_{j, t}
\end{aligned}
$$

where $\boldsymbol{\psi}_{j, t}^{g}(J)$ represents the GIRFs of variable $j, J$ represents the forecast horizon, $\boldsymbol{\delta}_{j, t}$ the selection vector equal to one on the $j$ th position and zero otherwise, and $\boldsymbol{F}_{t-1}$ the information set until $t-1$.

In addition, the GFEVD represent the part of the variance that one variable has over the others, and can be calculated by:

$$
\tilde{\phi}_{i j, t}^{g}(J)=\frac{\sum_{t=1}^{J-1} \boldsymbol{\psi}_{i j, t}^{2, g}(J)}{\sum_{j=1}^{N} \sum_{t=1}^{J-1} \boldsymbol{\psi}_{i j, t}^{2, g}(J)}
$$

with $\sum_{j=1}^{N} \widetilde{\phi}_{i j, t}^{N}(J)=1$ and $\sum_{i, j=1}^{N} \widetilde{\phi}_{i j, t}^{N}(J)=N$. From the GEFVD, the total connectedness index is constructed as follows:

$$
C_{t}^{g}(J)=\frac{\sum_{i, t=1, i \neq j}^{N} \tilde{\phi}_{i j, t}^{g}(J)}{\sum_{i, t=1}^{N} \tilde{\phi}_{i j, t}^{g}(J)} * 100
$$




$$
=\frac{\sum_{i, t=1, i \neq j}^{N} \tilde{\phi}_{i j, t}^{g}(J)}{N} * 100
$$

This connectedness index allows to compute the degree at which a shock in one variable is transmitted to other variables. The main advantages of the TVP-VAR-based measure of connectedness are the followings: (i) the measure adjusts immediately to events; (ii) the size of the rolling window is adjusted automatically, something that is an improvement of the Diebold and Yilmaz $(2009,2012)$ connectedness approach; (iii) it can also be applied to examine dynamic connectedness measures for limited time-series data (Antonakakis and Gabauer, 2017). ${ }^{3}$

\subsection{The TVP-VAR TO, FROM and NET connectedness indexes}

The connectedness index in Eq. (12) can be computed in order to estimate different directions of the relationship between the variables in the system. First, to measure the transmission of a shock on variable $i$ to all the other variables $j$ in the system, we compute the "total directional connectedness to others" (TO) as follows:

$$
C_{i \rightarrow j, t}^{g}(J)=\frac{\sum_{j=1, i \neq j}^{N} \tilde{\phi}_{j i, t}^{g}(J)}{\sum_{j=1}^{N} \tilde{\phi}_{j i, t}^{g}(J)} * 100
$$

Second, to calculate the transmission of a shock on variable $i$ received from all variables $j$ in the system, we compute the "total directional connectedness from others" (FROM) as follows:

$$
C_{i \leftarrow j, t}^{g}(J)=\frac{\sum_{j=1, i \neq j}^{N} \tilde{\phi}_{i j, t}^{g}(J)}{\sum_{i=1}^{N} \tilde{\phi}_{i j, t}^{g}(J)} * 100
$$

Furthermore, it to measure the net effect, i.e., the "net total directional connectedness" (NET), we subtract Equation (14) to Equation (13) by:

$$
C_{i, t}^{g}=C_{i \rightarrow j, t}^{g}(J)-C_{i \leftarrow j, t}^{g}(J)
$$

The NET index can take values below, equal or above zero. A positive value of the net total directional connectedness of variable $i\left(C_{i, t}^{g}>0\right)$ would indicate that variable $i$ influences the system more than it could be influenced by the system itself. Contrary, a

\footnotetext{
${ }^{3}$ This methodology has been also used in Gabauer and Gupta (2018) to analyze the economic policy uncertainty spillovers between the US and Japan, and in Antonakakis et al. (2020) to study dynamic connectedness measures of the four most traded foreign exchange rates against the US dollar.
} 
negative value of the net total directional connectedness of variable $i\left(C_{i, t}^{g}<0\right)$ would indicate that the net total directional connectedness of variable $i$ is driven by the system. Finally, a value of zero of the net total directional connectedness of variable $i\left(C_{i, t}^{g}=0\right)$ would indicate that variable $i$ neither has an influence, nor is influenced by the system.

\section{Data}

In this study we consider daily spot prices of three agricultural commodity indexes. The selected commodity indexes are sub-indexes of the Standard \& Poors Goldman Sachs Commodity Index (S\&P GSCI): the S\&P GSCI Softs, the S\&P GSCI Grains and the S\&P GSCI Livestock. ${ }^{4}$ The firsts two are also sub-indexes of the S\&P GSCI Agriculture index. On the one hand, the S\&P GSCI Softs commodity index, is an index for traded agricultural products defined as soft commodities: coffee, sugar, cocoa and cotton. The S\&P GSCI Grains, includes the agricultural commodities of Wheat (Chicago \& Kansas), Corn and Soybeans. Finally, the S\&P GSCI Livestock includes those commodities of Lean Hogs, Live Cattle and Feeder Cattle. These three sub-indexes jointly represent a significant portion of the S\&P GSCI commodity index, which provides investors with a reliable and publicly available benchmark for investment performance in the agricultural and livestock commodity markets (S\&P Dow Jones Indices: Index Methodology).

Apart from the price indexes, we include in our study the Coronavirus Media Coverage Index (MCI). This index, obtained from RavenPack, is used to measure the level of media coverage about the topic of the coronavirus. ${ }^{5}$ The Coronavirus MCI is obtained as the ratio between the number of news sources that covers the Coronavirus and the number of all the news sources. It is calculated daily and ranges from 0 to 100 (in percentage). A value of $50 \%$ means that half of the news sources within a day deal with news related with the SARS-CoV-2 crisis. This index has also been used in Cepoi (2020) and in Haroon and Rizvi (2020), who study the relationship between sentiment generated by coronavirus-related news and volatility levels in US equity markets.

Our sample covers the period from January 22, 2020 to July 31, 2020. The period comprises the heart of the COVID-19 crisis, including subsequent spikes as those on

\footnotetext{
${ }^{4}$ Data series have been retrieved from Datastream.

${ }^{5}$ RavenPack is a data analytics provider. They supply insights generated automatically from real-time news provided from over 22,000 sources of news and social media. Source: https://www.ravenpack.com/.
} 
March in Europe (March 17, 2020), and those the April and July on the US (April 25, 2020, and July 17, 2020). ${ }^{6}$

We compute daily returns from the daily spot prices as $r_{t}=\ln \left(P_{t} / P_{t-1}\right)$ where $r_{t}$ represents the daily return obtained from the natural logarithm between daily indexes prices, and $P_{t}$ and $P_{t-1}$ represents the indexes prices at the business days $t$ and $t-1$, respectively. Table 1 displays the main descriptive statistics and unitroot tests for the return and volatility of the three agricultural and livestock commodity indexes. In terms of returns, all variables show negative and close to zero means with the lowest value of $-0.14 \%$ for Livestock. Besides, all the variables present negative median values except to Softs that have a median equal to zero. The standard deviation varies from $0.97 \%$ for Grains to $2.01 \%$ for Livestock, respectively. Besides, the returns of Softs and Livestock show negative skewness, whereas those of Grains are positive. In addition, and all variables displays excess kurtosis. The standard unit root (Augmented DickeyFuller (ADF, 1979) and Phillips-Perron (PP, 1988)) and stationarity (KwiatkowskiPhillips-Schmidt-Shin (KPSS, 1992)) tests confirm that all log-return series are stationary. In terms of volatility, only Grains presents a negative mean. In this case, the median is positive for all variables, and the standard deviation ranges from $12.76 \%$ for Softs to $16.03 \%$ for Grains. Again, the variables of Softs and Livestock show negative skewness, whereas Grains present positive skewness. All variables display excess kurtosis, and the unit root and stationary tests confirm that all series are stationary.

\section{[INSERT TABLE 1 ABOUT HERE]}

\section{Empirical results}

This research analyses the connectedness in the system of the most relevant agricultural commodities (Softs, Grains and Livestock), and the Coronavirus Media Coverage Index (MCI). We apply the TVP-VAR approach proposed by Antonakakis and Gabauer (2017) which is useful in the context of our analysis, i.e., with short data series. We use timevarying connectedness measures based on variance decompositions from a TVP-VAR model applied to asset returns and volatilities to examine the degree at which these agricultural commodities have been affected by the SARS-CoV-2 crisis. We estimate total, FROM, TO and net dynamic connectedness measures, during the sample period

\footnotetext{
${ }^{6}$ See https://covidtracking.com/ for detailed information about the evolution of the pandemic in the US.
} 
between January 22, 2020 and July 31, 2020, whose aim is to analyse the impact of the global COVID-19 pandemic crisis on the dominant agricultural commodity markets.

5.1. Preliminary results about mean return and volatility connectedness and the total dynamic connectedness

We begin our analysis by estimating a 4-variable VAR model in which we include the variables of Softs, Grains, Livestock, and Coronavirus Media Coverage Index. The lag order, p, of the VAR model is chosen by means of a Bayes-Schwarz Information Criterion (BIC) in the reduced form model. We set the lag $\mathrm{p}=1$ and apply the VAR(1) model to approximate the models. We made a first approach to the study of the return and volatility connectedness in the system generated by the main agricultural commodities markets, also considering the Coronavirus MCI. In concrete, we examine the average values of the contribution that each agricultural commodity makes, first, TO the system and, second, FROM the system (in terms of both return and volatility), as well as the Coronavirus MCI included in the study.

\section{[INSERT FIGURE 2 ABOUT HERE]}

\section{[INSERT FIGURE 3 ABOUT HERE]}

Thus, Figure 2 shows the mean contribution TO the system of each variable (in return and volatility) around the SARS-CoV-2 coronavirus crisis. The most relevant transmitter (in mean) in terms of return is the Grain commodity market, being the Coronavirus MCI the less relevant transmitter in the system explored in this study. Nevertheless, this Coronavirus Media Coverage Index becomes the dominant transmitter (in mean), along with the Soft commodity market, in terms of volatility.

On the other hand, Figure 3 collects the mean contribution FROM the system to each variable (in terms of return and volatility). The first result we can clearly highlight is that the Coronavirus MCI shows substantially lower values than the commodity markets analysed when exploring the connectedness FROM the system studied in this paper. This phenomenon occurs not only in terms of return but also in terms of volatility. As far as the commodity markets are concerned, we observe few differences when studying the mean connectedness FROM the system in terms of return, showing the Soft, Grain and Livestock commodity markets high and similar values. However, when analysing the mean volatility connectedness FROM the system, Livestock would be the dominant receiver, while the Soft commodity market would be the least relevant receiver. 


\section{[INSERT FIGURE 4 ABOUT HERE]}

Figure 4 exhibits the dynamic total connectedness in terms of return and volatility in the system explored in this paper. The most relevant result evidences that the total connectedness of the system fluctuates over time (Gabauer and Gupta, 2018, among many others). It is interesting to note that in both panels of Figure 4 we observe a significant increase in the dynamic total connectedness at the heart of the global pandemic crisis caused by SARS-CoV-2 (shaded area). Specifically, in terms of return, the spike is observed in the month of March, coinciding with the declaration of global pandemic by World Health Organization (WHO) on March 11, 2020. In the case of dynamic total connectedness in terms of volatility, a significant peak is observed in April, approximately one month after that detected in the dynamic total return connectedness. Therefore, in both cases (return and volatility), the dynamic total connectedness in the system is sharpening at the epicentre of the global pandemic crisis, which could show a major impact on the agricultural commodity market studied in this paper.

\subsection{Net dynamic return and volatility connectedness: decomposition into dynamic} connectedness FROM and TO

To deepen the analysis of the dynamic connectedness in the system studied in this paper, which includes the Soft, Grain and Livestock commodity markets and the Coronavirus MCI, we analysed the net dynamic connectedness, as well as its decomposition into connectedness TO (Figure 5) and FROM (Figure 6) in terms of both return and volatility.

\section{[INSERT FIGURE 5 ABOUT HERE]}

As commented in the previous subsection, the dominant transmitter TO the system (Figure 5) in terms of return (Panel A) is the Grain commodity market, then Soft, then Livestock commodity markets, maintaining this order throughout the period analysed characterized by the crisis caused by COVID-19. On the other hand, the Coronavirus MCI shows the lowest values of transmission to the system in terms of return along the sample. Nevertheless, it is noteworthy that the coronavirus MCI shows a significant peak as a transmitter at the beginning of the period analysed, just before the heart of the global pandemic crisis.

Regarding the dynamic volatility connectedness TO (Panel B), we observe a much more complex behaviour than in the case of dynamic return connectedness. First, the estimated connectedness values are very similar in the system studied in this paper, mainly at the 
beginning of the sample period. In addition, the Coronavirus MCI is the dominant transmitter in terms of volatility during the first weeks of the study period. Then, the Soft commodity market becomes the major transmitter during the epicentre of the pandemic, becoming again the Coronavirus MCI at the end of the heart of the crisis period. In the final weeks of our analysis, the Grain commodity market appears as the most relevant transmitter TO the system. The Livestock agricultural commodity market appears as the least important transmitter in the system studied in this paper, mainly in the second half of the sample, observing values much lower than the rest of the commodity markets analysed. Finally, it is remarkable that the coronavirus MCI and all the commodity markets exhibits high variability at the launch of the sample period, just before the heart of the COVID-19 crisis.

Finally, with regard to Figure 5, it should be noted that in both panels we perceive an interesting surge in the dynamic return and volatility connectedness TO the system in the centre of the COVID-19 pandemic crisis, in concrete, in March, in terms of return and delayed a few weeks in terms of volatility.

\section{[INSERT FIGURE 6 ABOUT HERE]}

Figure 6 collects the dynamic total return (Panel A) and volatility (Panel B) connectedness FROM the system to the commodity markets and the Coronavirus MCI. In general, the first major result we found is that the status among the commodity markets analysed (Soft, Grain and Livestock) is maintained throughout the entire pandemic period examined, even in relation to the Coronavirus MCI. Second, this Coronavirus MCI is by far the lowest receiver of dynamic connectedness FROM the system, both in terms of return and volatility. Third, while in terms of return the biggest receivers of connectedness FROM the system are the Grain and Soft commodity markets, being at a short distance the Livestock market, however, in terms of volatility, this last one (Livestock) becomes the commodity market that presents the highest value as connectedness receiver FROM the system. Bellow it would be the Soft commodity market and, lastly, and at a distance, the Grain commodity market. Fourth, we return to the phenomenon previously identified, which consists of a peak in the dynamic connectedness FROM in terms of return in March 2020, which is delayed to the month of April 2020, in the case of the dynamic volatility connectedness FROM the system. Finally, it is also interesting to note that the Livestock commodity market presents a significant gap with respect to the rest of the system's 
elements during the first weeks of the study. From the end of February this gap narrowed, mainly with the Soft commodity market.

\section{[INSERT FIGURE 7 ABOUT HERE]}

Lastly, as the difference between connectedness TO and FROM in both return and volatility, Figure 7 shows the net dynamic total return and volatility connectedness of the system analysed in this paper that includes the most relevant agricultural commodity markets (Soft, Grain and Livestock) and the Coronavirus MCI. This connectedness measure summarizes the previous results obtained in this paper. First, the Coronavirus MCI is the most important transmitter TO the system, not only in terms of return, but also in terms of volatility, as well as during the whole sample period. Moreover, the highest values of the net dynamic return connectedness are in the first weeks of the sample, just before the epicentre of the coronavirus crisis period, and, also, in March 2020, coinciding with the declaration of the SARS-CoV-2 pandemic by the WHO. However, the net dynamic volatility connectedness reaches the highest level not only at the beginning of the sample period, but also in the centre of the COVID-19 pandemic crisis, in concrete in April 2020. Second, in general, the Grain agricultural commodity market show a positive net dynamic return and volatility connectedness, predominantly during the heart of the coronavirus crisis. Nonetheless, the net dynamic return and volatility connectedness exhibits negative values just prior to the declaration of the SARS-CoV-2 pandemic crisis (January and February 2020).

Third, except in some cases where the net dynamic connectedness shows occasionally positive values in the Livestock commodity market, in the rest of the cases, such connectedness is negative, both in terms of return and volatility. Moreover, the net dynamic return connectedness has a negative peak at the beginning of the pandemic crisis epicentre, after the institutional pandemic declaration, and it shows a huge gap with respect to the other agricultural commodity markets from April 2020 to the end of the sample. In terms of volatility, the worst results are found at the beginning of the analysis period (end of January and beginning of February), as well as at the end of May 2020. Since then, this commodity market exhibits a path of evolution that is just the opposite of what we see in the Soft agricultural commodity market. Fourth, the Soft commodity market has a very erratic behaviour. Thus, the net dynamic connectedness in terms of return goes from positive to negative several times throughout the sample period analysed. Furthermore, we can identify a small positive peak in the month of February 
and another one at the beginning of March 2020, after the declaration of a global epidemic, from which this net dynamic return connectedness starts to decrease until reaching the lowest level in April 2020. From there, the net dynamic connectedness in terms of return recovers, becoming positive until the end of the epicentre of the pandemic crisis caused by COVID-19. Lastly, values are negative for the whole month of July. As regards the net dynamic volatility connectedness, this is positive, reaching quite high values at the beginning of the sample period of our paper. At the end of February 2020 it begins to fall to negative values, which it maintains throughout the sample period, except for a small upturn at the end of April, which places this connectedness at positive values, but only for a few days. Finally, we observe a completely opposite behaviour between the net dynamic connectedness of the Coronavirus MCI and that shown by the Livestock commodity market, both in terms of return and volatility. However, the rest of the agricultural commodity markets analysed (Soft and Grain) share evolution with the Coronavirus MCI in many moments of the sample, in both net dynamic return and volatility connectedness.

\section{Concluding remarks}

This paper examines the dynamic return and volatility connectedness in the system consisting of the three dominant agricultural commodity markets (Soft, Grain and Livestock) and the Coronavirus Media Coverage Index (MCI) extracted from RavenPack. In the context of an extension of the TVP-VAR connectedness methodology proposed by Antonakakis and Gabauer (2017), this study explores the net dynamic connectedness, distinguishing between TO and FROM connectedness, in both return and volatility. In addition, this methodology lets us to classify industrial metals as net transmitters TO and net receivers FROM the system.

About the sample period, this paper focuses on analysing the impact of the COVID-19 pandemic crisis, which is having repercussions worldwide comparable to the global financial crisis caused by subprime mortgages. In particular, to analyse the effect of this global pandemic outbreak on the most relevant agricultural commodity markets, our study uses the previously mentioned Coronavirus Media Coverage Index (MCI), which has been applied in some very recent papers. In concrete, our sample period ranges from January 22, 2020 to July 31, 2020, in order to conduct a thorough examination of the epicentre of the SARS-CoV-2 pandemic. 
Fresh and interesting results for the agricultural commodity markets are reached. First, the dynamic total return and volatility connectedness fluctuates over time, reaching a peak during the heart of the global pandemic crisis, primarily in the dynamic total return connectedness (March 2020) and later in the volatility one (April 2020). This result would confirm the impact of the COVID-19 global pandemic on the agricultural commodity markets, both in terms of dynamic total return and volatility connectedness.

As previously mentioned, we apply a recent methodology to split the net dynamic connectedness into connectedness FROM and TO (the system), as well as in terms of return and volatility. As far as the dynamic connectedness TO the system is concerned, we find a similar behaviour but on different levels between the agricultural commodity markets in the case of return connectedness TO. Specifically, the dominant transmitter TO the system is the Grain commodity market, then the Soft market and, lastly, the Livestock market. The Coronavirus MCI exhibits the least values of the dynamic return connectedness TO the system. However, in terms of volatility, the gap between agricultural commodity markets is lower, stressing the Coronavirus MCI (at the beginning of the sample) and the Soft commodity market (in April-May 2020) as some of the major transmitters TO the system. On the other hand, the Livestock commodity market shows the lowest dynamic volatility connectedness from the middle of the sample analysed in this paper onwards.

With regard to the dynamic connectedness FROM, the Coronavirus MCI appears as the less relevant receiver FROM the system, not only in terms of dynamic return connectedness, but also in volatility. In the first case, the evolution of the return connectedness between the agricultural commodity markets is quite like that observed in the dynamic return connectedness TO, although the peak observed in March 2020 is higher for the Soft commodity market. In terms of volatility, the Livestock commodity market would appear as the dominant receiver FROM the system, being the least relevant receiver the grain commodity market. It is interesting to note the peaks observed in the dynamic return connectedness FROM in the second half of March and in the volatility one in the middle of Aril 2020.

Lastly, when considering the net effect of the above two connectedness measures (net dynamic total connectedness), the Coronavirus MCI emerges as the most valuable net transmitter to the system both in terms of return and volatility. Furthermore, the agricultural commodity markets studied in this paper show the following order: The Grain 
commodity market, then the Soft market and finally the Livestock market, in both net dynamic return and volatility connectedness measures. The Livestock commodity market exhibit negative values in both measures during the full sample period. Moreover, this commodity market presents negative peaks in terms of return at the introduction of the pandemic's heart and in terms volatility in the centre of the SARS-CoV-2 outbreak crisis. Our results have important policy implications due to the worldwide relevance of the agricultural commodity markets. The Livestock agricultural commodity market seem to be the most affected market because of the COVID-19 pandemic crisis, showing a high persistence not only in return but also in volatility. As agricultural commodity markets are essential markets, it is necessary to adopt important policy actions aimed at guaranteeing price stability during periods of economic turbulence.

As regards future lines of research, a first extension of the work would be to expand the study to other agricultural commodity markets, as well as to apply this recent TVP-VAR connectedness methodology to alternative commodity and cryptocurrency markets, in the context of the global SARS-CoV-2 pandemic crisis. Another interesting research would consist in explores the impact of the Coronavirus Media Coverage Index (MCI) on the most relevant international sector indices in terms of return and volatility. 


\section{References}

Antonakakis, N. and Gabauer, D. (2017). Refined Measures of Dynamic Connectedness based on TVP-VAR. MPRA Paper No. 78282, 1-15.

Antonakakis, N., Chatziantoniou, I. and Gabauer, D. (2020). Refined Measures of Dynamic Connectedness based on Time-Varying Parameter Vector Autoregressions. Journal of Risk and Financial Management, 13, 84.

Bakas, D., \& Triantafyllou, A. (2018). The impact of uncertainty shocks on the volatility of commodity prices. Journal of International Money and Finance, 87, 96-111. https://doi.org/10.1016/j.jimonfin.2018.06.001

Bakas, D., \& Triantafyllou, A. (2020). Commodity price volatility and the economic uncertainty of pandemics. Economics Letters, 193, 109283. https://doi.org/10.1016/j.econlet.2020.109283

Cabrera, B. L., \& Schulz, F. (2016). Volatility linkages between energy and agricultural commodity prices. Energy Economics, 54, 190-203. https://doi.org/10.1016/j.eneco.2015.11.018

Cepoi, C. O. (2020). Asymmetric dependence between stock market returns and news during COVID-19 financial turmoil. Finance Research Letters, forthcoming. https://doi.org/10.1016/j.frl.2020.101658

Chevallier, J., \& Ielpo, F. (2013). Volatility spillovers in commodity markets. Applied Economics Letters, 20(13),

1211-1227. https://doi.org/10.1080/13504851.2013.799748

Creti, A., Joëts, M., \& Mignon, V. (2013). On the links between stock and commodity markets' volatility. Energy Economics, 37, 16-28. https://doi.org/10.1016/j.eneco.2013.01.005

Conlon, T., \& McGee, R. (2020). Safe haven or risky hazard? Bitcoin during the COVID19 bear market. Finance Research Letters, 35101607. https://doi.org/10.1016/j.frl.2020.101607

Corbet, S., Larkin, C. and Lucey, B. (2020b). The contagion effects of the COVID-19 pandemic: Evidence from gold and cryptocurrencies. Finance Research Letters, 35, 101554. https://doi.org/10.1016/j.frl.2020.101554

Dahl, R. E., Oglend, A., \& Yahya, M. (2019). Dynamics of volatility spillover in commodity markets: Linking crude oil to agriculture. Journal of Commodity Markets, 100111. https://doi.org/10.1016/j.jcomm.2019.100111

Delatte, A. L., \& Lopez, C. (2013). Commodity and equity markets: Some stylized facts from a copula approach. Journal of Banking \& Finance, 37(12), 5346-5356. https://doi.org/10.1016/j.jbankfin.2013.06.012

Du, X., \& McPhail, L. L. (2012). Inside the black box: the price linkage and transmission between energy and agricultural markets. The Energy Journal,33(2). https://doi.org/10.5547/01956574.33.2.8 
Engle, R. F., Ghysels, E., \& Sohn, B. (2013). Stock market volatility and macroeconomic fundamentals. Review of Economics and Statistics,95(3), 776-797. https://doi.org/10.1162/REST_a_00300

Gabauer, D. and Gupta, R. (2018). On the transmission mechanism of country-specific and international economic uncertainty spillovers: Evidence from a TVP-VAR connectedness decomposition approach. Economics Letters, 171, 63-71.

Gargano, A., \& Timmermann, A. (2014). Forecasting commodity price indexes using macroeconomic and financial predictors. International Journal of Forecasting, 30(3), 825-843. https://doi.org/10.1016/j.ijforecast.2013.09.003

Goodell, J. W. (2020). COVID-19 and finance: Agendas for future research. Finance Research Letters, 101512. https://doi.org/10.1016/j.frl.2020.101512

Groß-Klußmann, A., \& Hautsch, N. (2011). When machines read the news: Using automated text analytics to quantify high frequency news-implied market reactions. Journal of Empirical Finance, 18(2), 321-340. https://doi.org/10.1016/j.jempfin.2010.11.009

Hamilton, J. D., \& Lin, G. (1996). Stock market volatility and the business cycle. Journal of applied econometrics, 11(5), 573-593. https://doi.org/10.1002/(SICI)1099$\underline{1255(199609)}$

Kaltalioglu, M., \& Soytas, U. (2011). Volatility spillover from oil to food and agricultural raw material markets. Modern 71. https://doi:10.4236/me.2011.22011

Kang, S. H., McIver, R., and Yoon, S.-M. (2017). Dynamic spillover effects among crude oil, precious metal, and agricultural commodity futures markets. Energy Economics, $62,19-32$.

Kaplanski, G., \& Levy, H. (2010). Sentiment and stock prices: The case of aviation disasters. Journal of Financial Economics, 95(2), 174-201. https://doi.org/10.1016/j.jfinec0.2009.10.002

Koirala, K. H., Mishra, A. K., D'Antoni, J. M., \& Mehlhorn, J. E. (2015). Energy prices and agricultural commodity prices: Testing correlation using copulas method. Energy, 81, 430-436. https://doi.org/10.1016/j.energy.2014.12.055

Koop, G., Pesaran, M. H., \& Potter, S. M. (1996). Impulse response analysis in nonlinear multivariate models. Journal of Econometrics, 74(1), 119-147. https://doi.org/10.1016/0304-4076(95)01753-4

Ludvigson, S. C., \& Ng, S. (2009). Macro factors in bond risk premia. The Review of Financial Studies, 22(12), 5027-5067. https://doi.org/10.1093/rfs/hhp081

Mensi, W., Beljid, M., Boubaker, A., \& Managi, S. (2013). Correlations and volatility spillovers across commodity and stock markets: Linking energies, food, and gold. Economic Modelling, 32, 15-22. https://doi.org/10.1016/j.econmod.2013.01.023 
Mensi, W., Hammoudeh, S., \& Kang, S. H. (2015). Precious metals, cereal, oil and stock market linkages and portfolio risk management: Evidence from Saudi Arabia. Economic Modelling, 51, 340-358. https://doi.org/10.1016/j.econmod.2015.08.005

Nagayev, R., Disli, M., Inghelbrecht, K., \& Ng, A. (2016). On the dynamic links between commodities and Islamic equity. Energy Economics, 58, 125-140. https://doi.org/10.1016/j.eneco.2016.06.011

Nazlioglu, S., Erdem, C., \& Soytas, U. (2013). Volatility spillover between oil and agricultural commodity markets. Energy Economics, 36, 658-665. https://doi.org/10.1016/j.eneco.2012.11.009

Paye, B. S. (2012). 'Déjà vol': Predictive regressions for aggregate stock market volatility using macroeconomic variables. Journal of Financial Economics, 106(3), 527-546. https://doi.org/10.1016/j.jfineco.2012.06.005

Pesaran, H. H., \& Shin, Y. (1998). Generalized impulse response analysis in linear multivariate models. Economics Letters, 58(1), 17-29. https://doi.org/10.1016/S0165$\underline{1765(97) 00214-0}$

Prokopczuk, M., Stancu, A., \& Symeonidis, L. (2019). The economic drivers of commodity market volatility. Journal of International Money and Finance, 98, 102063. https://doi.org/10.1016/j.jimonfin.2019.102063

Reboredo, J. C. (2012). Do food and oil prices co-move?. Energy policy, 49, 456-467. https://doi.org/10.1016/j.enpol.2012.06.035

Renault, T. (2017). Intraday online investor sentiment and return patterns in the US stock market. Journal of Banking \& Finance, 84, 25-40. https://doi.org/10.1016/j.jbankfin.2017.07.002

Salisu, A. A., Akanni, L., \& Raheem, I. (2020a). The COVID-19 global fear index and the predictability of commodity price returns. Journal of Behavioral and Experimental Finance, 100383. https://doi.org/10.1016/j.jbef.2020.100383

Salisu, A. A., Ebuh, G. U., \& Usman, N. (2020b). Revisiting oil-stock nexus during COVID-19 pandemic: Some preliminary results. International Review of Economics \& Finance, 69, 269-284. https://doi.org/10.1016/j.iref.2020.06.023

Serra, T. (2011). Volatility spillovers between food and energy markets: A semiparametric approach. Energy Economics, 33(6), 1155-1164. https://doi.org/10.1016/j.eneco.2011.04.003

Sharif, A., Aloui, C., \& Yarovaya, L. (2020). COVID-19 pandemic, oil prices, stock market, geopolitical risk and policy uncertainty nexus in the US economy: Fresh evidence from the wavelet-based approach. International Review of Financial Analysis, 101496. 
Silvennoinen, A., \& Thorp, S. (2013). Financialization, crisis and commodity correlation dynamics. Journal of International Financial Markets, Institutions and Money, 24, 4265. https://doi.org/10.1016/j.intfin.2012.11.007

Sims, C. A. (1980). Macroeconomics and reality. Econometrica: journal of the Econometric Society, 1-48. https://doi.org/10.2307/1912017

Su, Z., Fang, T., \& Yin, L. (2017). The role of news-based implied volatility among US financial markets. Economics Letters, 157, 24-27. https://doi.org/10.1016/j.econlet.2017.05.028

Tetlock, P. C. (2007). Giving content to investor sentiment: The role of media in the stock market. The Journal of finance, 62(3), 1139-1168. https://doi.org/10.1111/j.1540$\underline{6261.2007 .01232 . x}$

Tetlock, P. C., Saar-Tsechansky, M., \& Macskassy, S. (2008). More than words: Quantifying language to measure firms' fundamentals. The Journal of Finance, 63(3), 1437-1467. https://doi.org/10.1111/j.1540-6261.2008.01362.x

Tiwari, A. K., Nasreen, S., Shahbaz, M., \& Hammoudeh, S. (2020). Time-frequency causality and connectedness between international prices of energy, food, industry, agriculture and metals. Energy Economics, 85, 104529. https://doi.org/10.1016/j.eneco.2019.104529

Wang, J., Shao, W., \& Kim, J. (2020). Analysis of the impact of COVID-19 on the correlations between crude oil and agricultural futures. Chaos, Solitons \& Fractals, 109896. https://doi.org/10.1016/j.chaos.2020.109896

Yahya, M., Oglend, A., \& Dahl, R. E. (2019). Temporal and spectral dependence between crude oil and agricultural commodities: A wavelet-based copula approach. Energy Economics, 80, 277-296. https://doi.org/10.1016/j.eneco.2019.01.011

Yip, P. S., Brooks, R., Do, H. X., \& Nguyen, D. K. (2020). Dynamic volatility spillover effects between oil and agricultural products. International Review of Financial Analysis, 101465. https://doi.org/10.1016/j.irfa.2020.101465

Zhang, D. and Broadstock, D. C. (2018). Global financial crisis and rising connectedness in the international commodity markets. International Review of Financial Analysis, 68,101239 . 
Table 1. Descriptive statistics of the main categories of the agricultural commodity markets (Softs, Grains and Livestock) and the Media coverage index (in returns and volatility)

\begin{tabular}{|c|c|c|c|c|c|c|}
\hline & \multicolumn{5}{|c|}{ Returns } & \multicolumn{3}{c|}{ Volatility } \\
\hline & Softs & Grains & Lifestock & Softs & Grains & Lifestock \\
\hline Mean & -0.0007 & -0.0009 & -0.0014 & 0.0046 & -0.0016 & 0.0008 \\
\hline Median & 0.0000 & -0.0016 & -0.0006 & 0.0005 & 0.0003 & 0.0026 \\
\hline Maximum & 0.0333 & 0.0347 & 0.0530 & 0.3933 & 0.7691 & 0.4698 \\
\hline Minimum & -0.0418 & -0.0263 & -0.0623 & -0.3776 & -0.6713 & -0.6104 \\
\hline Std. Dev. & 0.0137 & 0.0097 & 0.0201 & 0.1276 & 0.1603 & 0.1369 \\
\hline Skewness & -0.3789 & 0.4617 & -0.3176 & -0.0432 & 0.3350 & -0.9449 \\
\hline Kurtosis & 3.3796 & 4.1985 & 3.9408 & 4.1721 & 9.6814 & 8.8849 \\
\hline JB & 4.1307 & $13.1614^{* * *}$ & $7.4104^{* *}$ & $7.9420^{* *}$ & $259.2694^{* * *}$ & $219.6692^{* * *}$ \\
\hline ADF & $-10.8053^{* * *}$ & $-9.7960^{* * *}$ & $-9.9865^{* * *}$ & $-11.7359^{* * *}$ & $-11.5575^{* * *}$ & $-11.8770^{* * *}$ \\
\hline PP & $-10.8037^{* * *}$ & $-9.9677^{* * *}$ & $-9.9027^{* * *}$ & $-11.8299^{* * *}$ & $-11.5853^{* * *}$ & $-11.9905^{* * *}$ \\
\hline KPSS & 0.5179 & 0.2080 & 0.3376 & 0.0528 & 0.0324 & 0.2537 \\
\hline Obs. & 138 & 138 & 138 & 138 & 138 & 138 \\
\hline
\end{tabular}

Notes: This table collects the descriptive statistics of daily agricultural commodity and the Coronavirus Media Coverage Index (MCI) returns and volatility. The sample period ranges from January 22, 2020 to July 31, 2020, around the COVID-19 pandemic crisis. They include mean, median, minimum (Min.) and maximum (Max.) values, standard deviation (Std. Dev.) and Skewness and Kurtosis measures. JB denotes the statistic of the Jarque-Bera test for normality. The results of the augmented Dickey-Fuller (ADF, 1979) and Phillips-Perron (PP, 1988) unit root tests, and the Kwiatkowski et al. (KPSS, 1992) stationarity test are also reported in the last three lines. As usual, ${ }^{*},{ }^{* * *},{ }^{* * *}$ indicate statistical significance at the $10 \%, 5 \%$ and $1 \%$ levels, respectively. 
Figure 1. Evolution of the spot prices of the agricultural commodity indexes

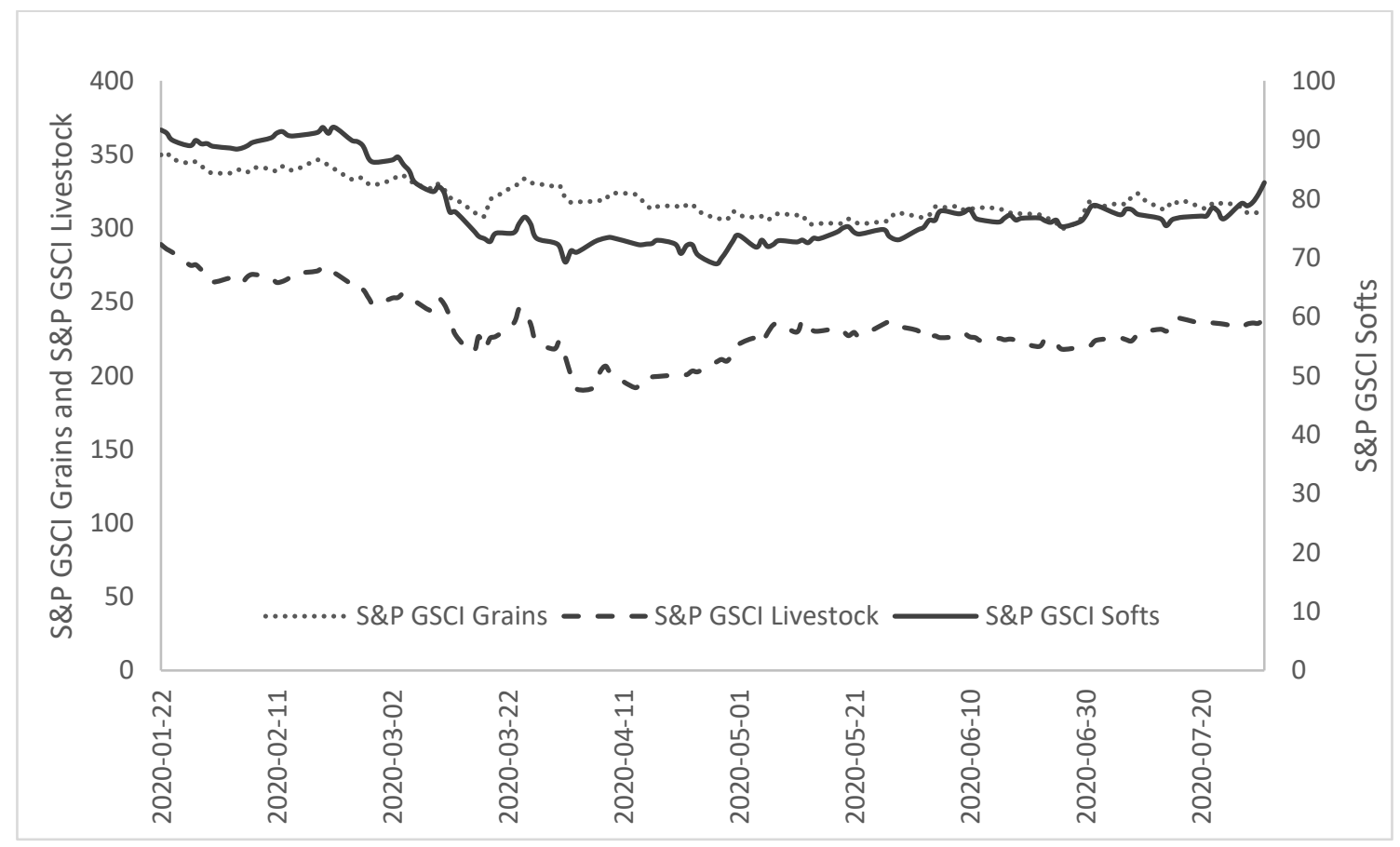

Notes: This figure displays the evolution of the spot prices of the S\&P GSCI Softs, the S\&P GSCI Grains and the S\&P GSCI Livestock indexes. The data has been retrieved from Datastream and the period ranges from January 22, 2020 to July 31, 2020. 
Figure 2. Mean contribution TO the system of each variable

Panel A: In returns

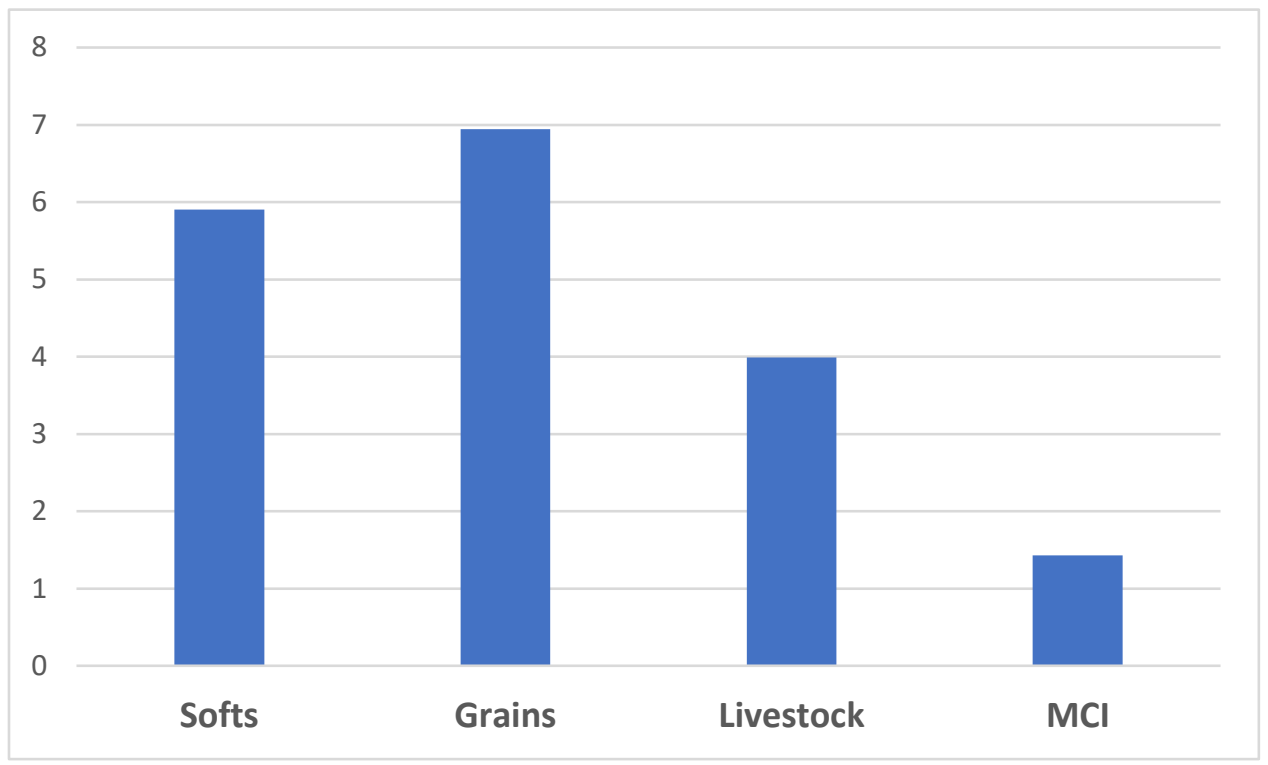

Panel B: In volatility

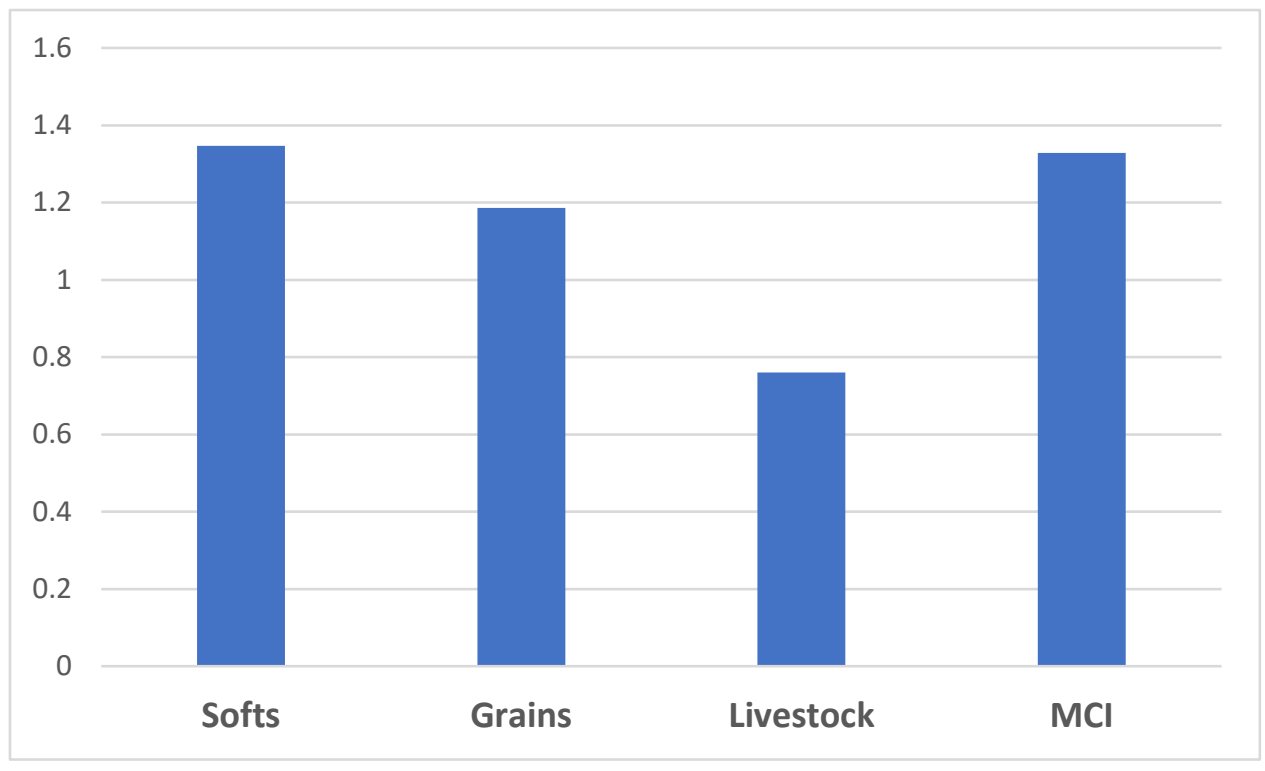

Notes: We study the return and volatility connectedness between the most relevant agricultural commodity markets (Softs, Grains and Livestock) and the Coronavirus MCI (Media Coverage Index) - obtained from RavenPack-, within the TVP-VAR framework (Antonakakis and Gabauer, 2017). 
Figure 3. Mean contribution FROM the system to each variable

Panel A: In returns

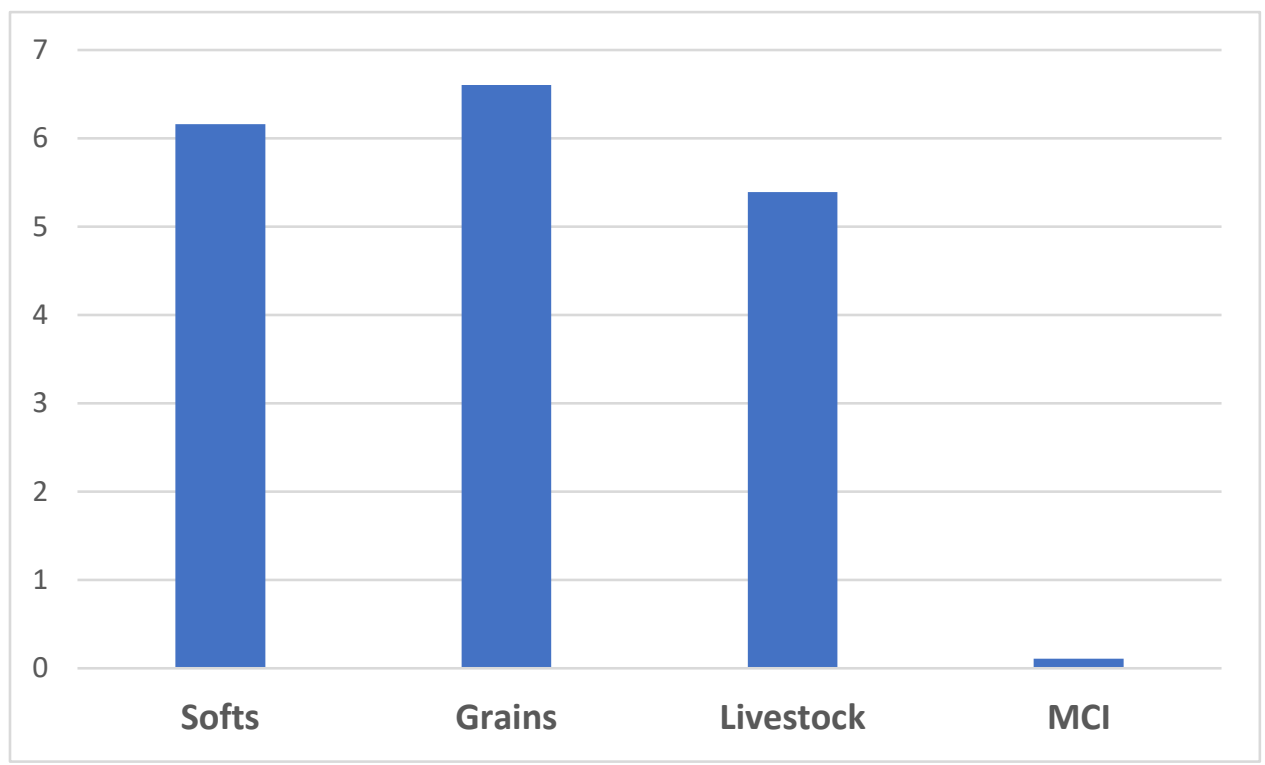

Panel B: In volatility

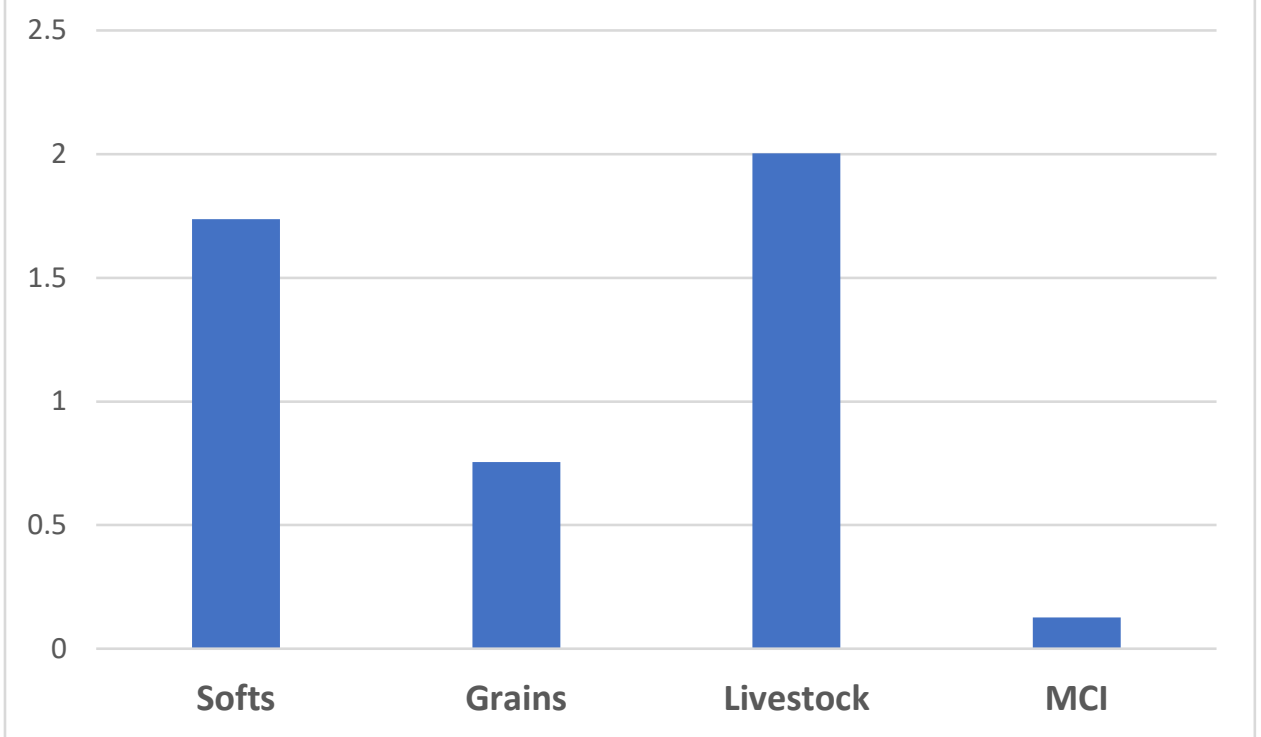

Notes: We study the return and volatility connectedness between the most relevant agricultural commodity markets (Softs, Grains and Livestock) and the Coronavirus MCI (Media Coverage Index) - obtained from RavenPack-, within the TVP-VAR framework (Antonakakis and Gabauer, 2017). 
Figure 4. Dynamic total connectedness over time

Panel A: In returns

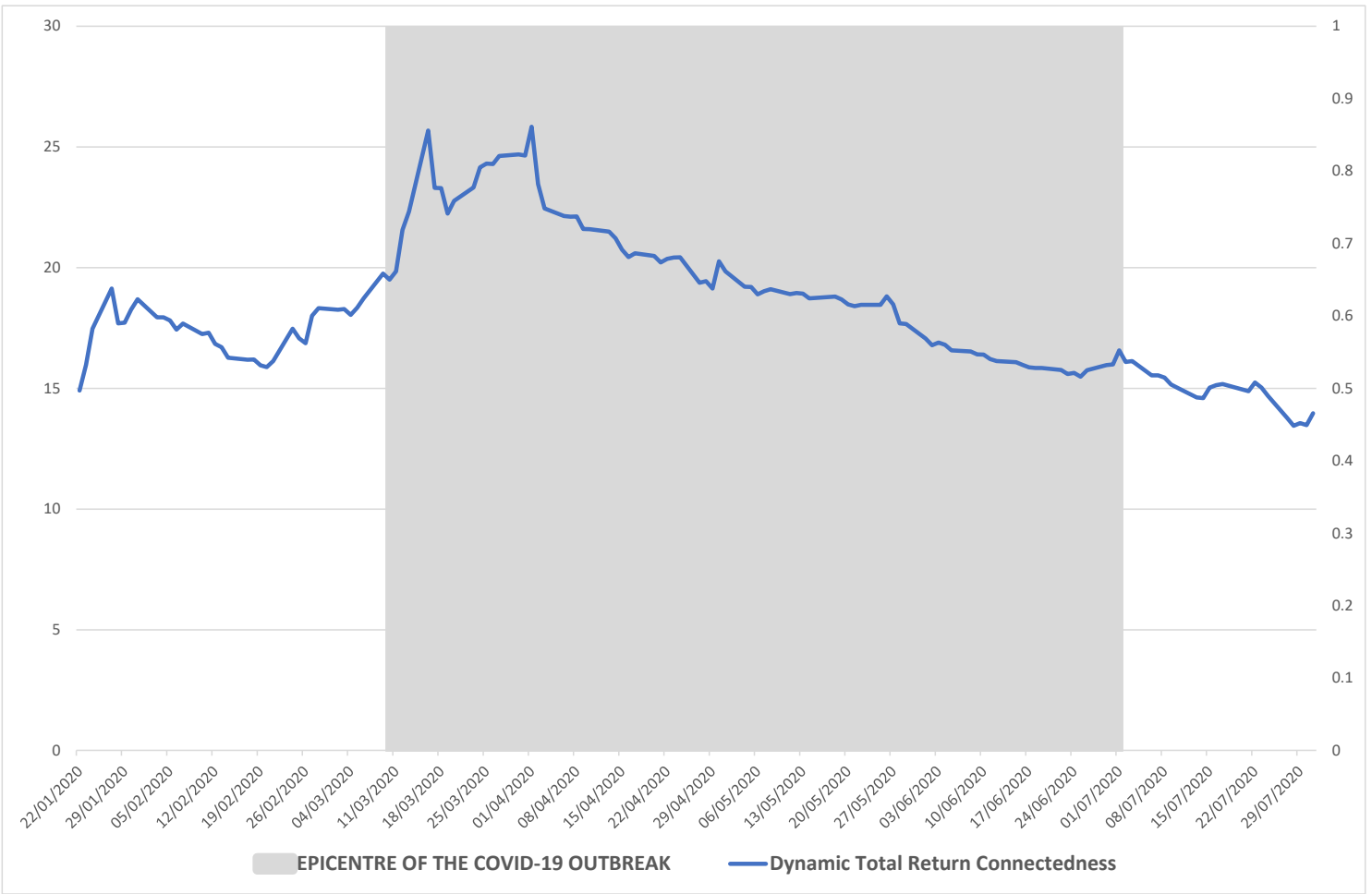

Panel B: In volatility

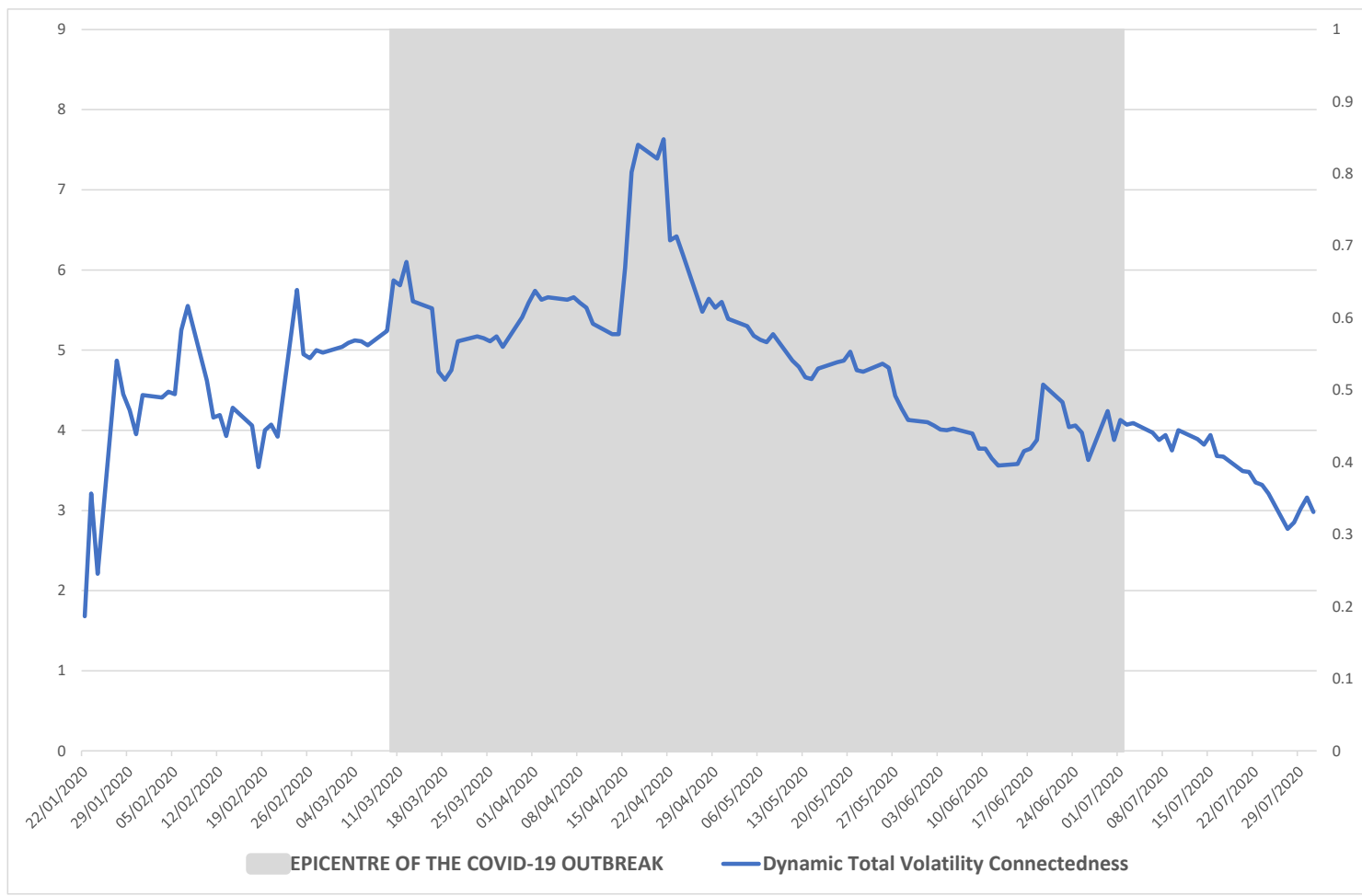

Notes: We study the return and volatility connectedness between the most relevant agricultural commodity markets (Softs, Grains and Livestock) and the Coronavirus MCI (Media Coverage Index) - obtained from RavenPack-, within the TVP-VAR framework (Antonakakis and Gabauer, 2017). 
Figure 5. Dynamic contribution of the industrial metals TO the system

Panel A: In returns

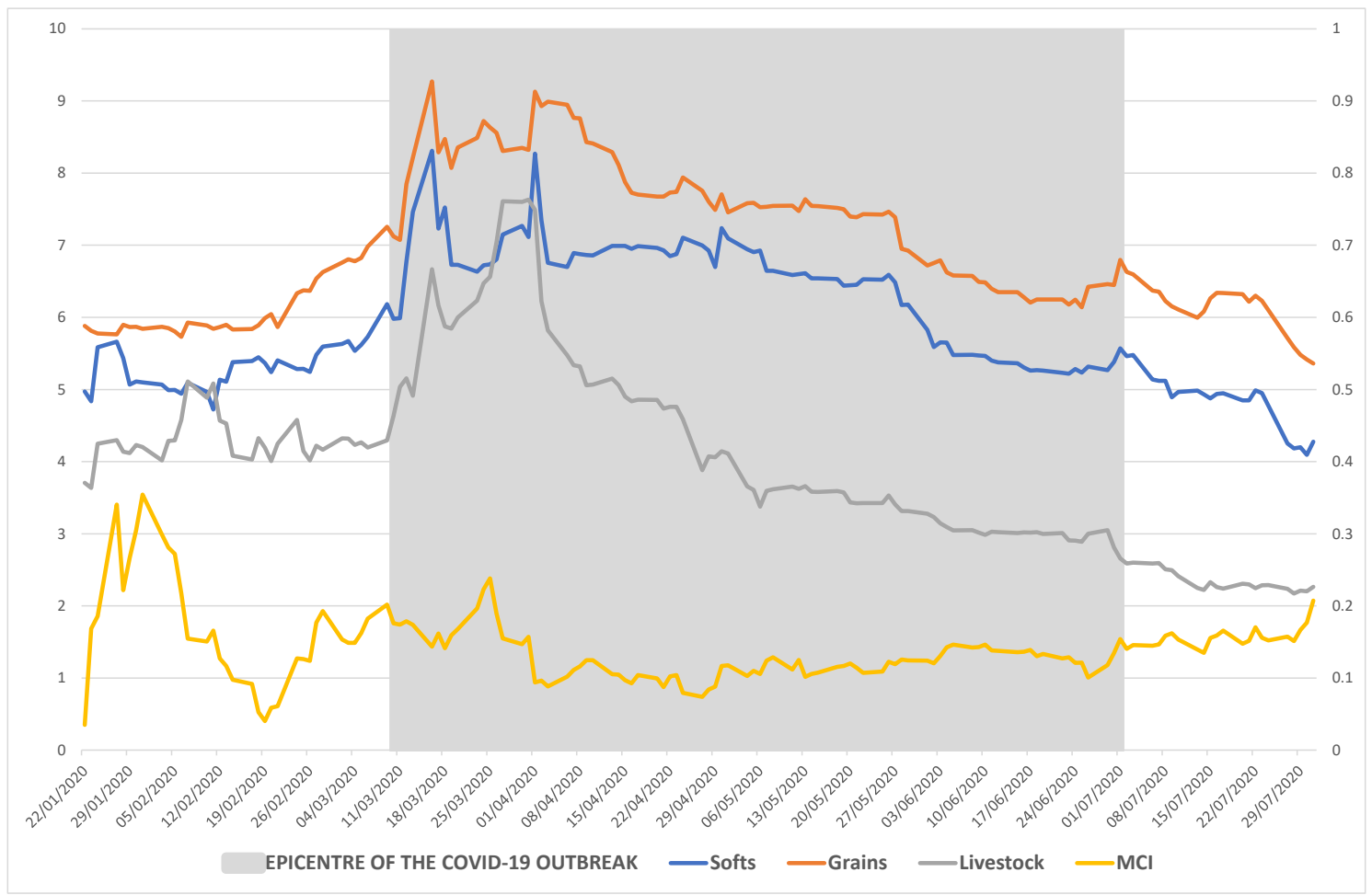

Panel B: In volatility

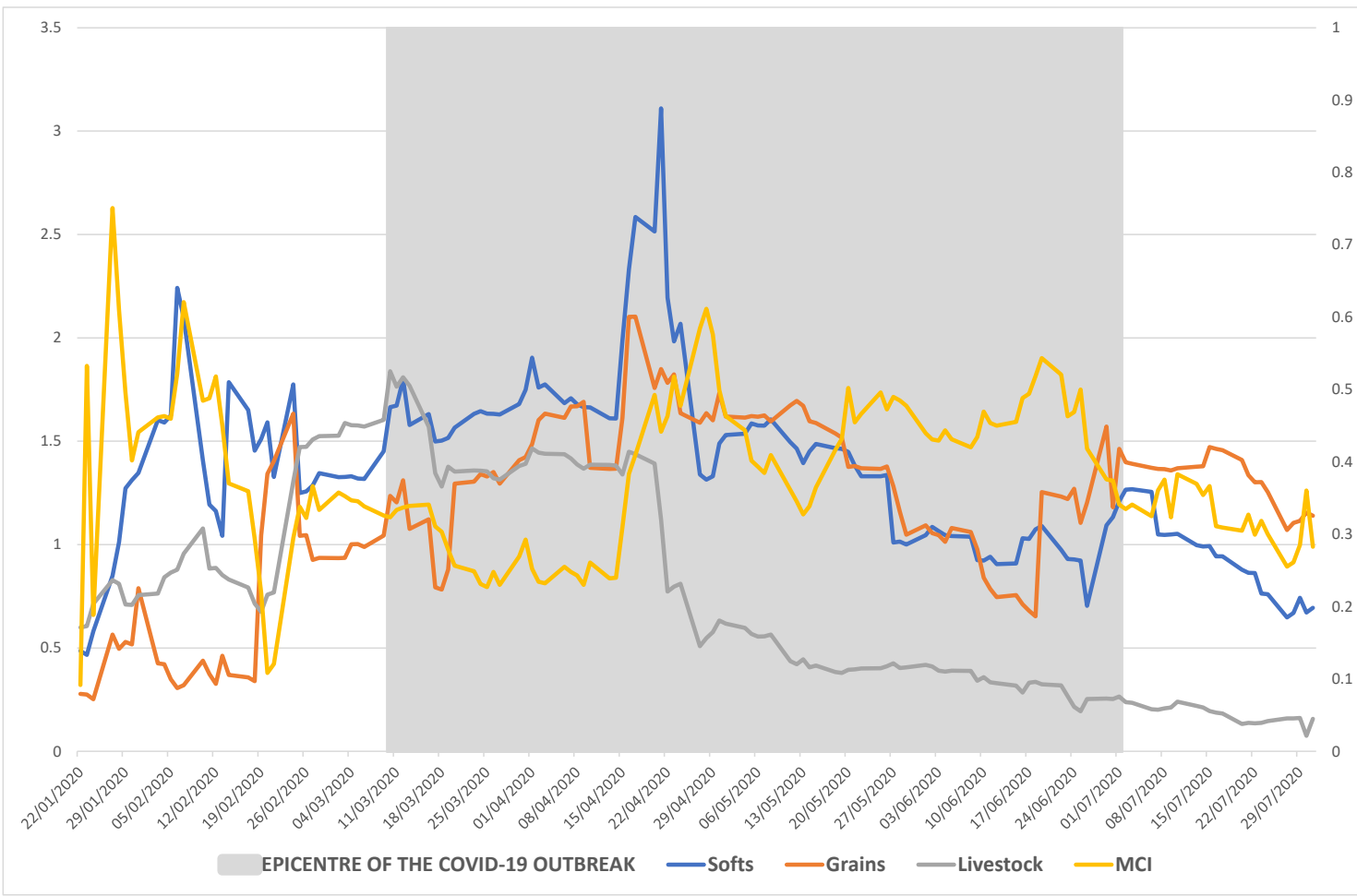

Notes: We study the return and volatility connectedness between the most relevant agricultural commodity markets (Softs, Grains and Livestock) and the Coronavirus MCI (Media Coverage Index) - obtained from RavenPack-, within the TVP-VAR framework (Antonakakis and Gabauer, 2017). 
Figure 6. Dynamic contribution FROM the system to the industrial metals

Panel A: In returns

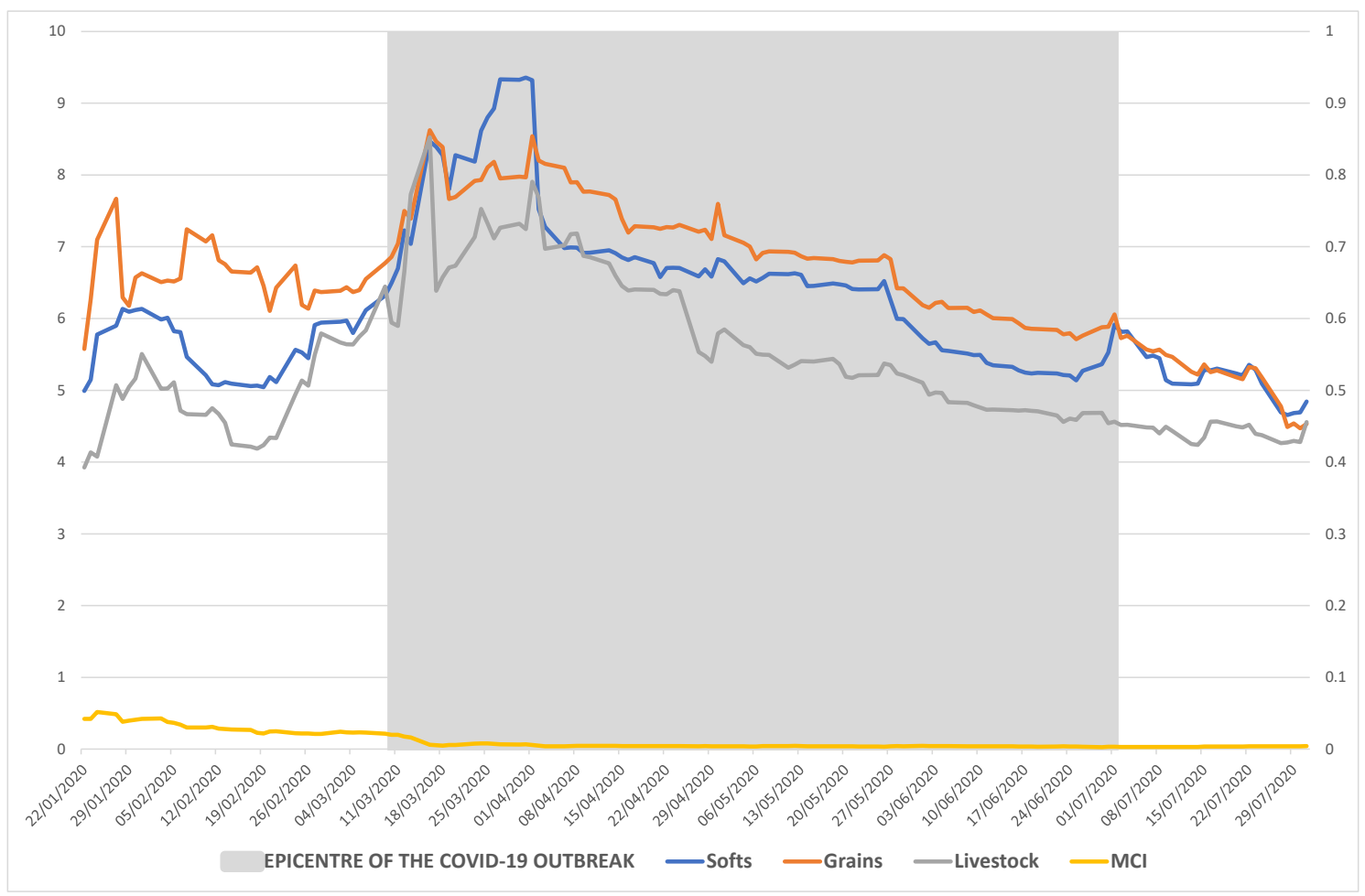

Panel B: In volatility

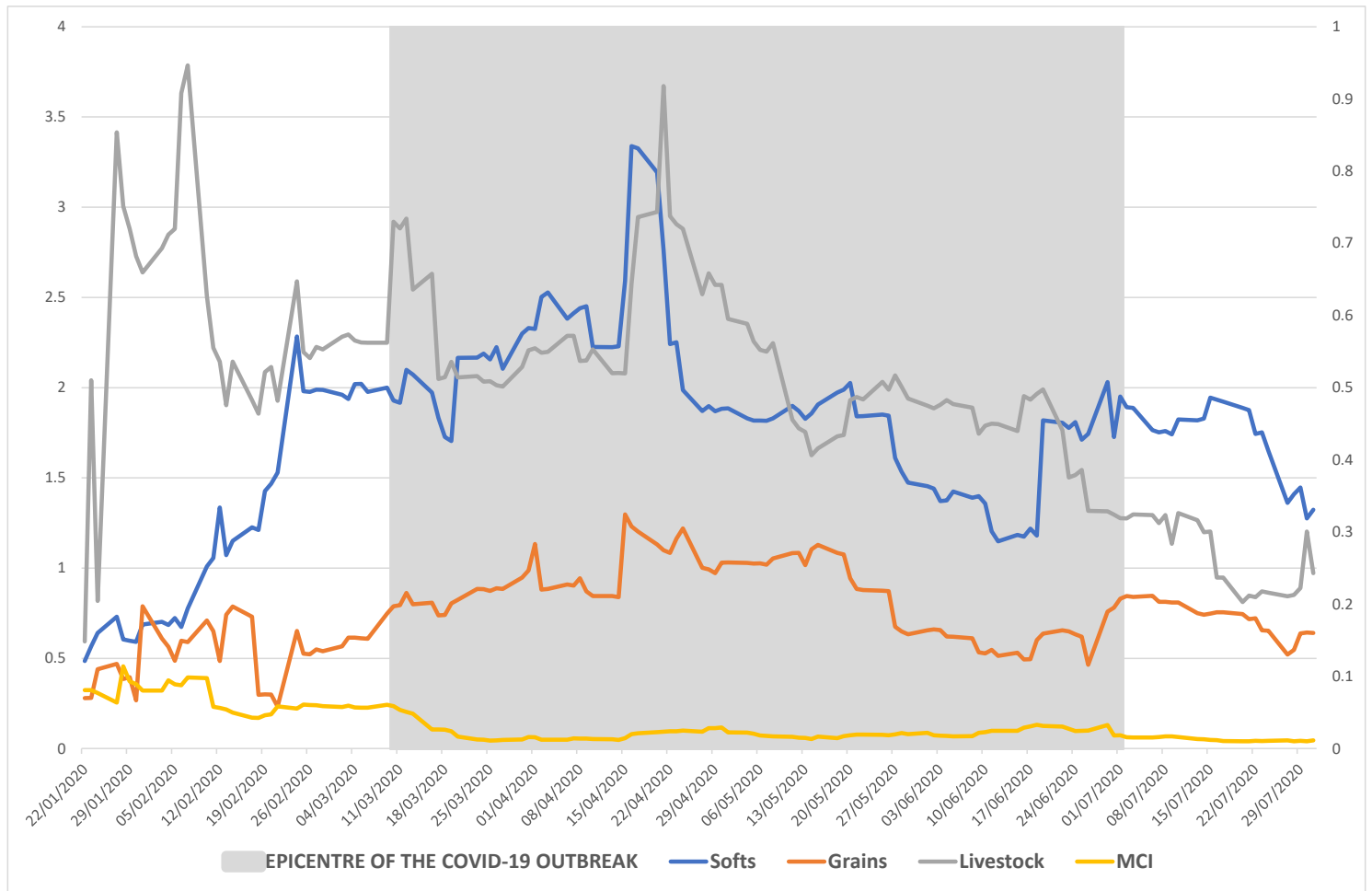

Notes: We study the return and volatility connectedness between the most relevant agricultural commodity markets (Softs, Grains and Livestock) and the Coronavirus MCI (Media Coverage Index) - obtained from RavenPack-, within the TVP-VAR framework (Antonakakis and Gabauer, 2017). 
Figure 7. Net dynamic total connectedness

Panel A: In returns

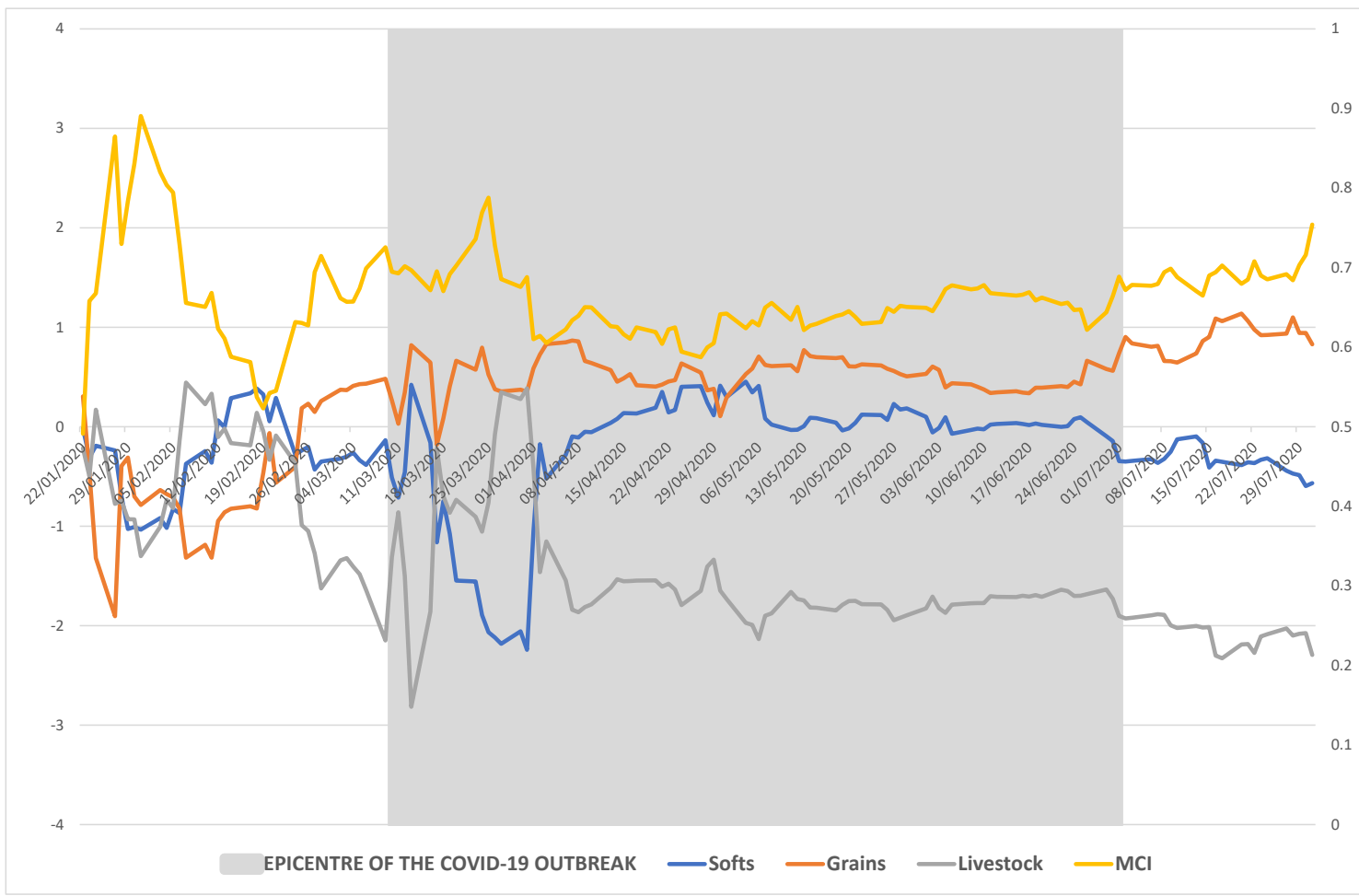

Panel B: In volatility

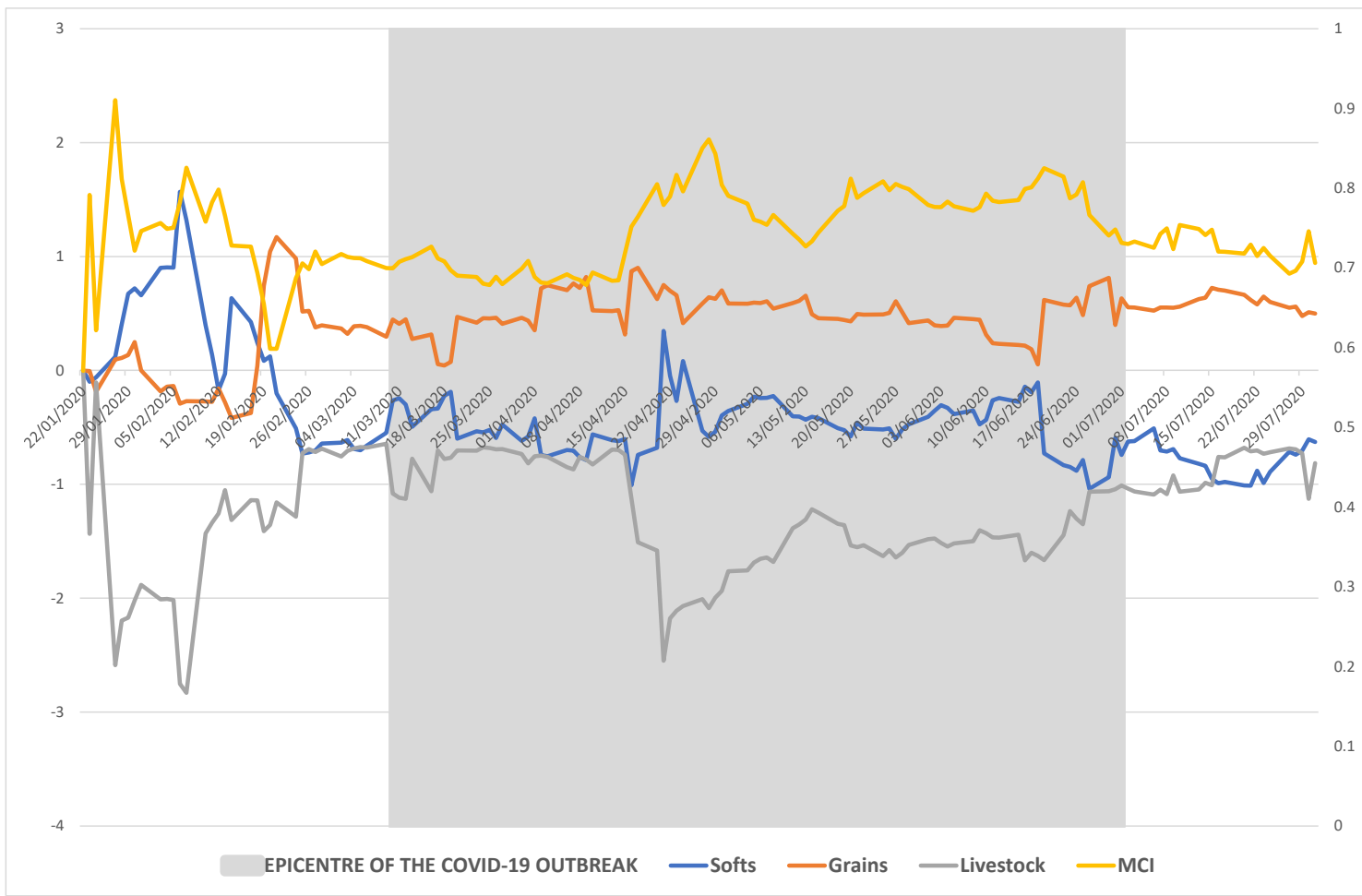

Notes: We study the return and volatility connectedness between the most relevant agricultural commodity markets (Softs, Grains and Livestock) and the Coronavirus MCI (Media Coverage Index) - obtained from RavenPack-, within the TVP-VAR framework (Antonakakis and Gabauer, 2017). 
Figures

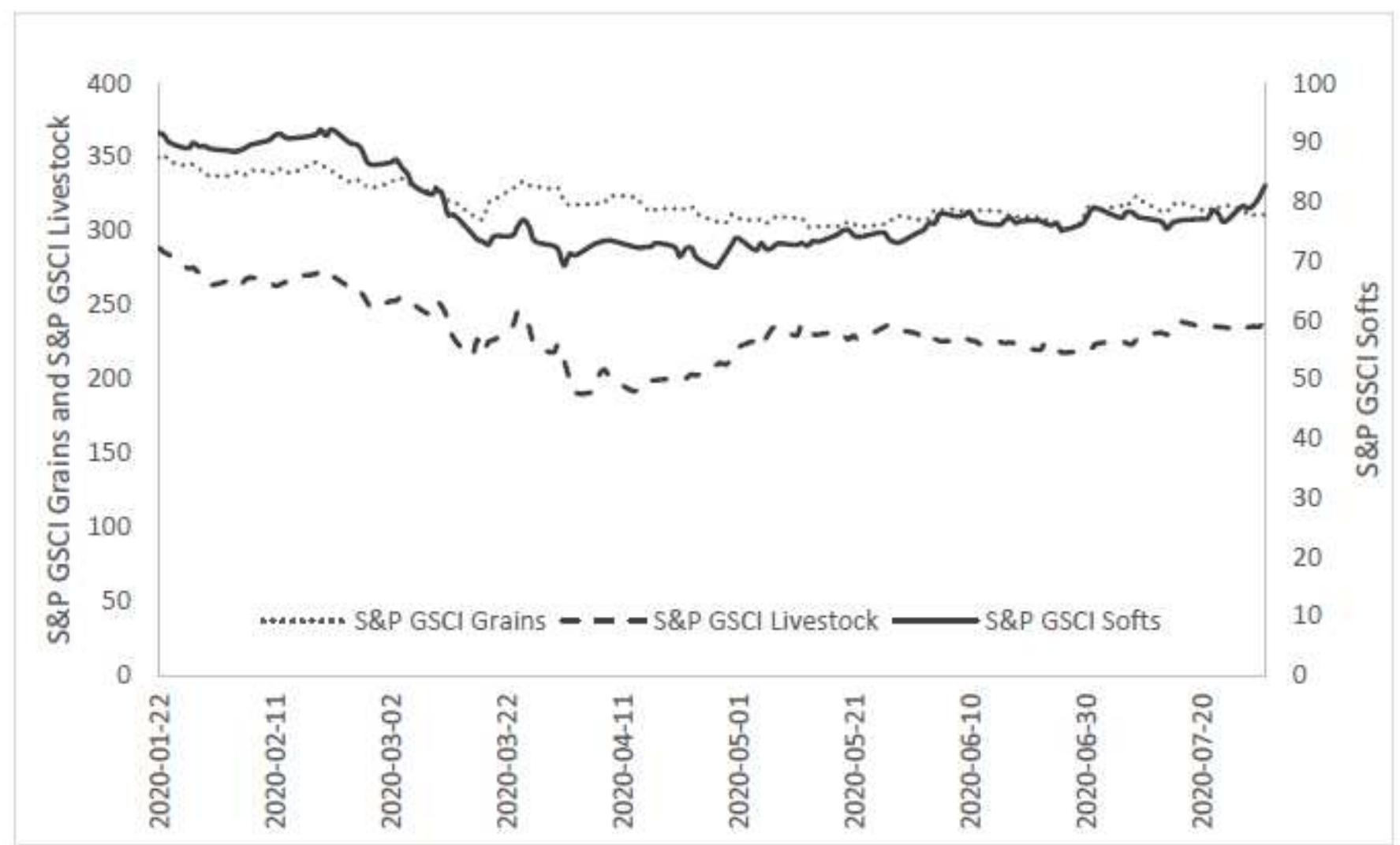

Notes: This figure displays the evolution of the spot prices of the S\&P GSCI Softs, the S\&P GSCI Grains and the S\&P GSCI Livestock indexes. The data has been retrieved from Datastream and the period ranges from January 22, 2020 to July 31, 2020.

\section{Figure 1}

Evolution of the spot prices of the agricultural commodity indexes 
Panel A: In returns

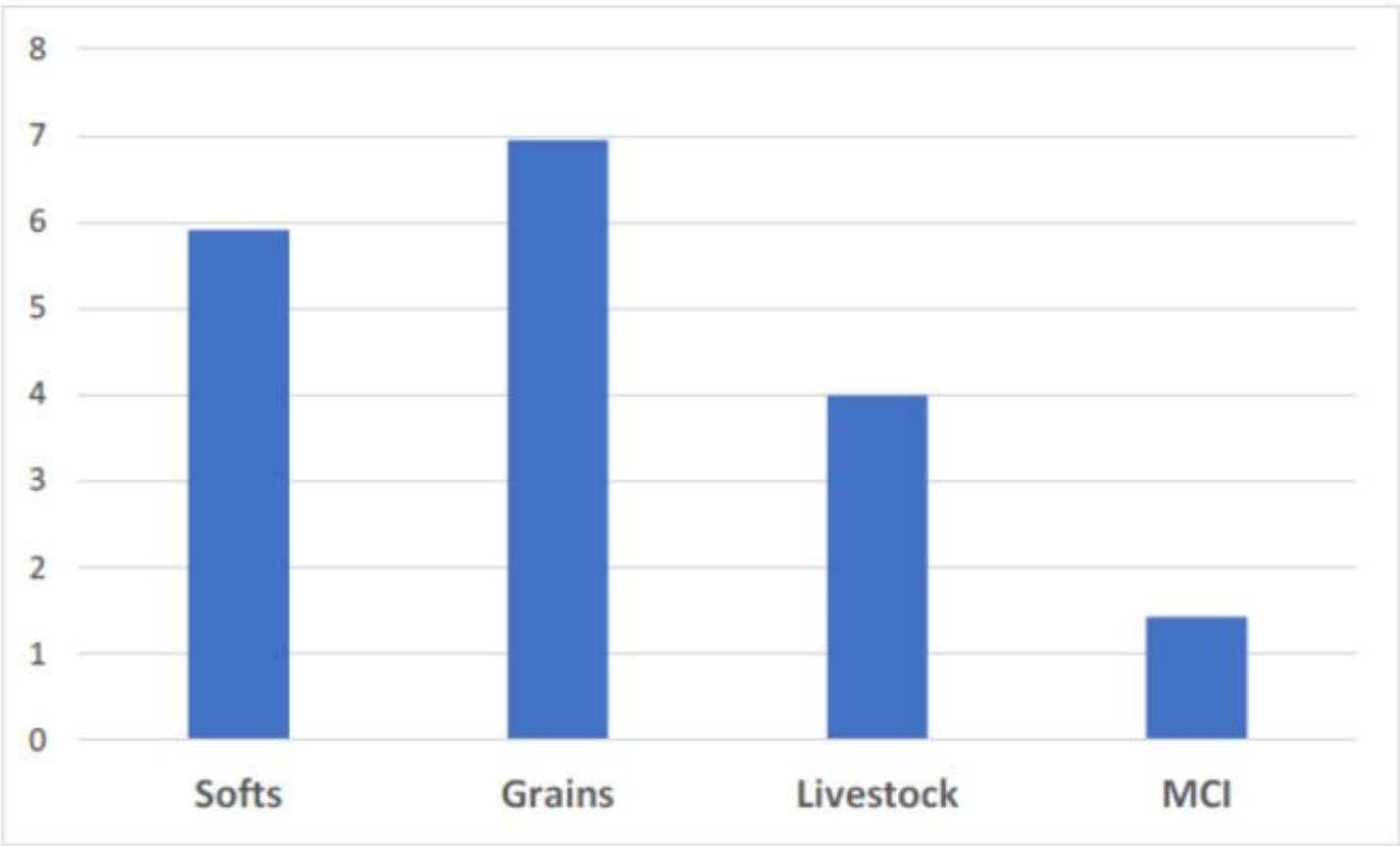

Panel B: In volatility

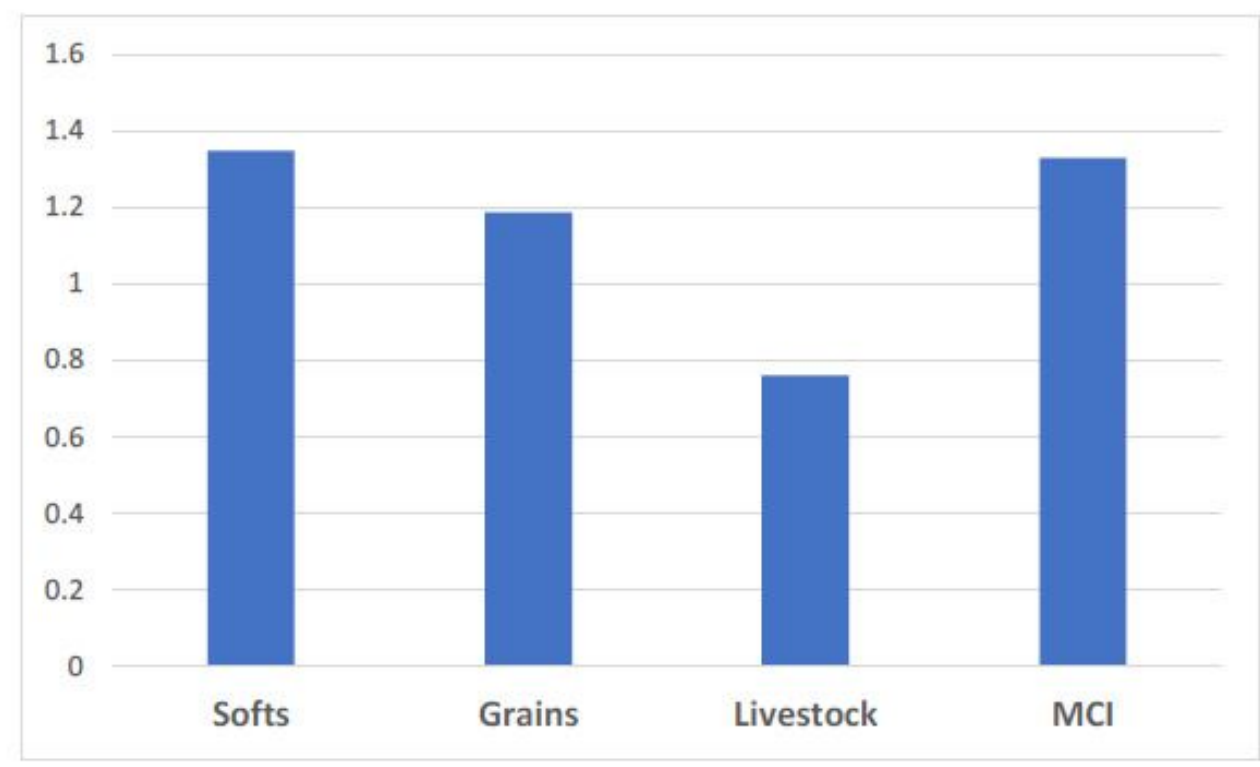

Notes: We study the return and volatility connectedness between the most relevant agricultural commodity markets (Softs, Grains and Livestock) and the Coronavirus MCI (Media Coverage Index) - obtained from RavenPack-, within the TVP-VAR framework (Antonakakis and Gabauer, 2017).

\section{Figure 2}

Mean contribution TO the system of each variable 
Panel A: In returns

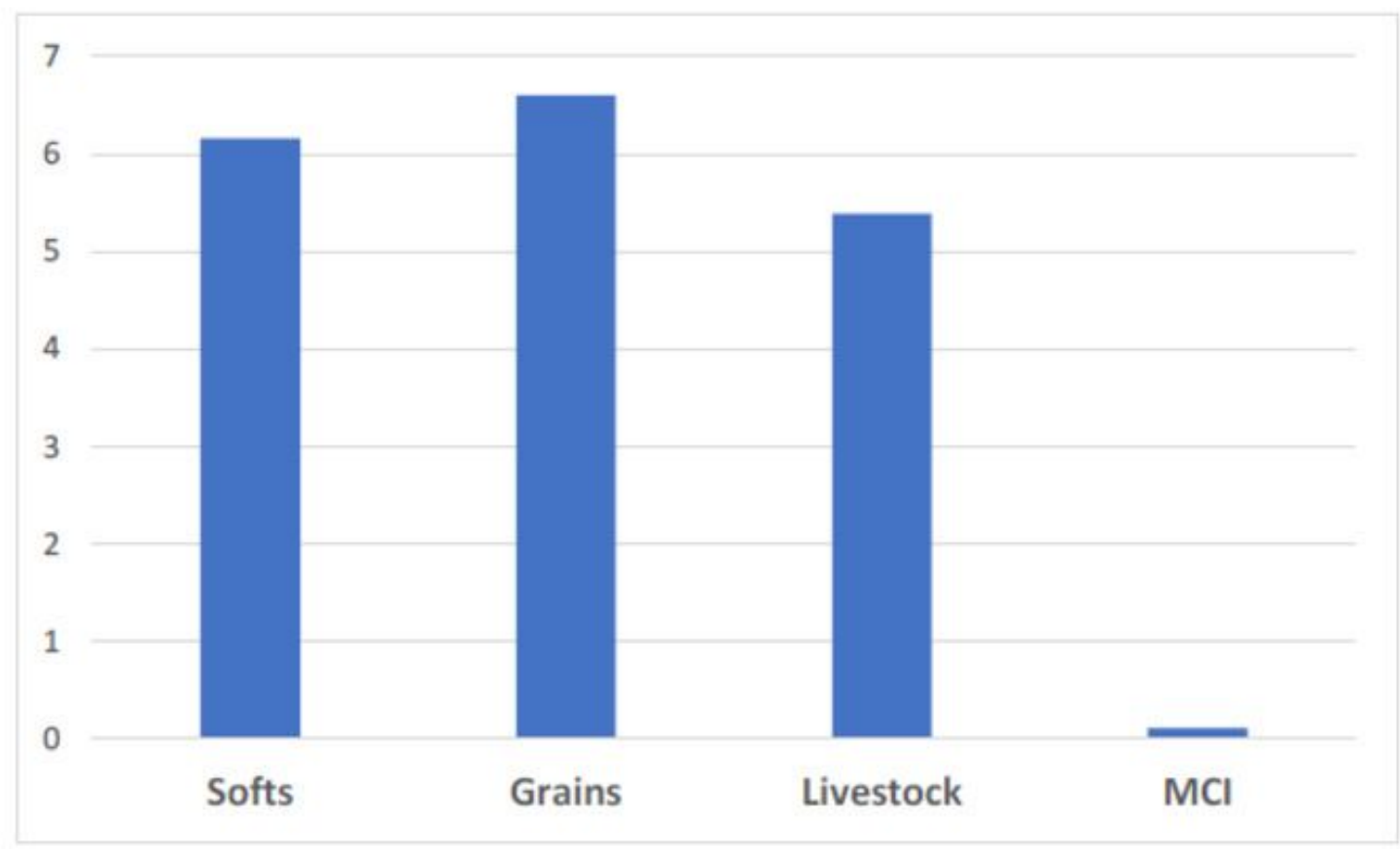

Panel B: In volatility

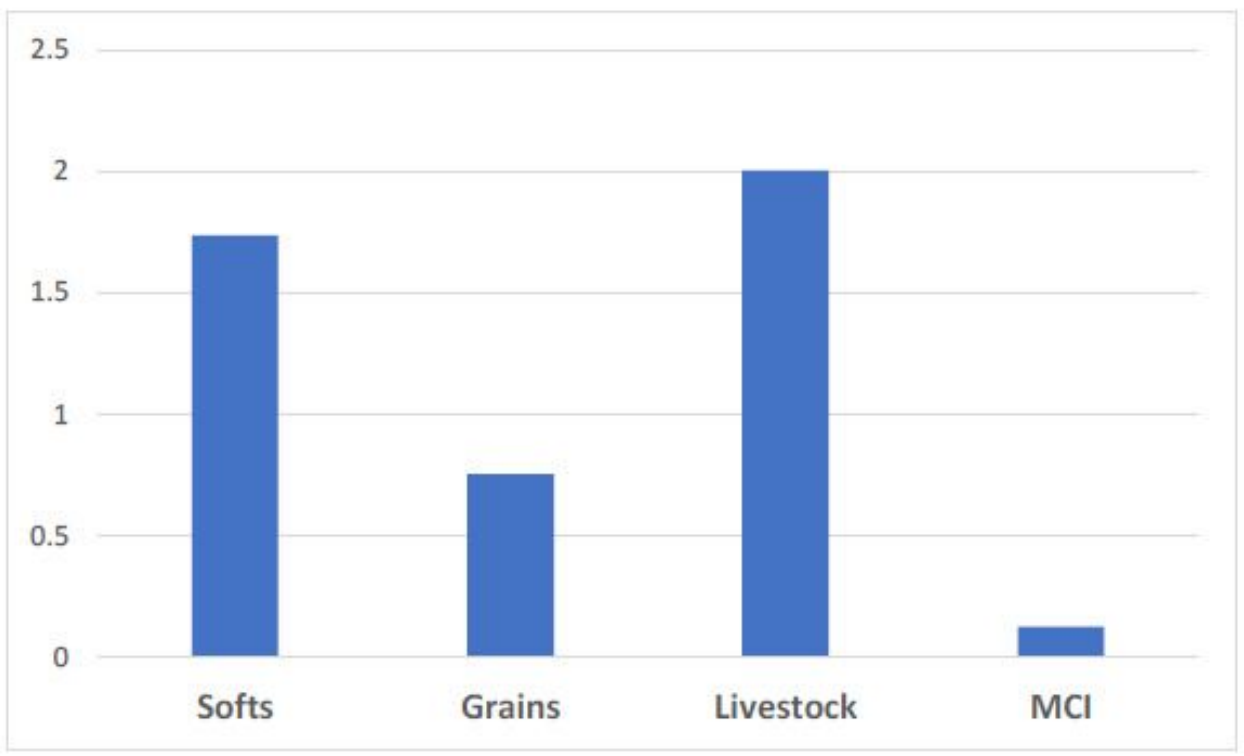

Notes: We study the return and volatility connectedness between the most relevant agricultural commodity markets (Softs, Grains and Livestock) and the Coronavirus MCI (Media Coverage Index) - obtained from RavenPack-, within the TVP-VAR framework (Antonakakis and Gabauer, 2017).

\section{Figure 3}

Mean contribution FROM the system to each variable 


\section{Panel A: In returns}

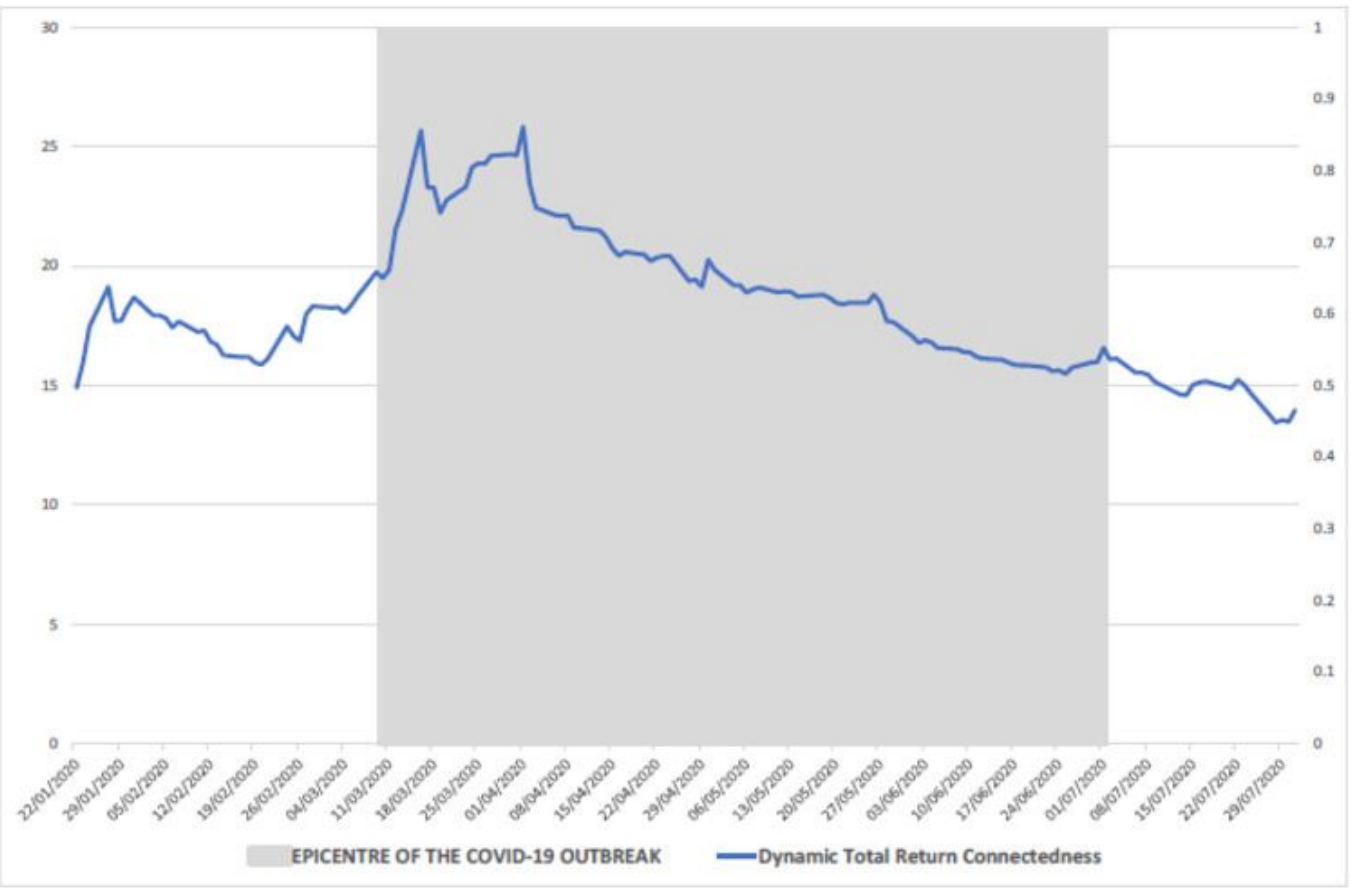

Panel B: In volatility

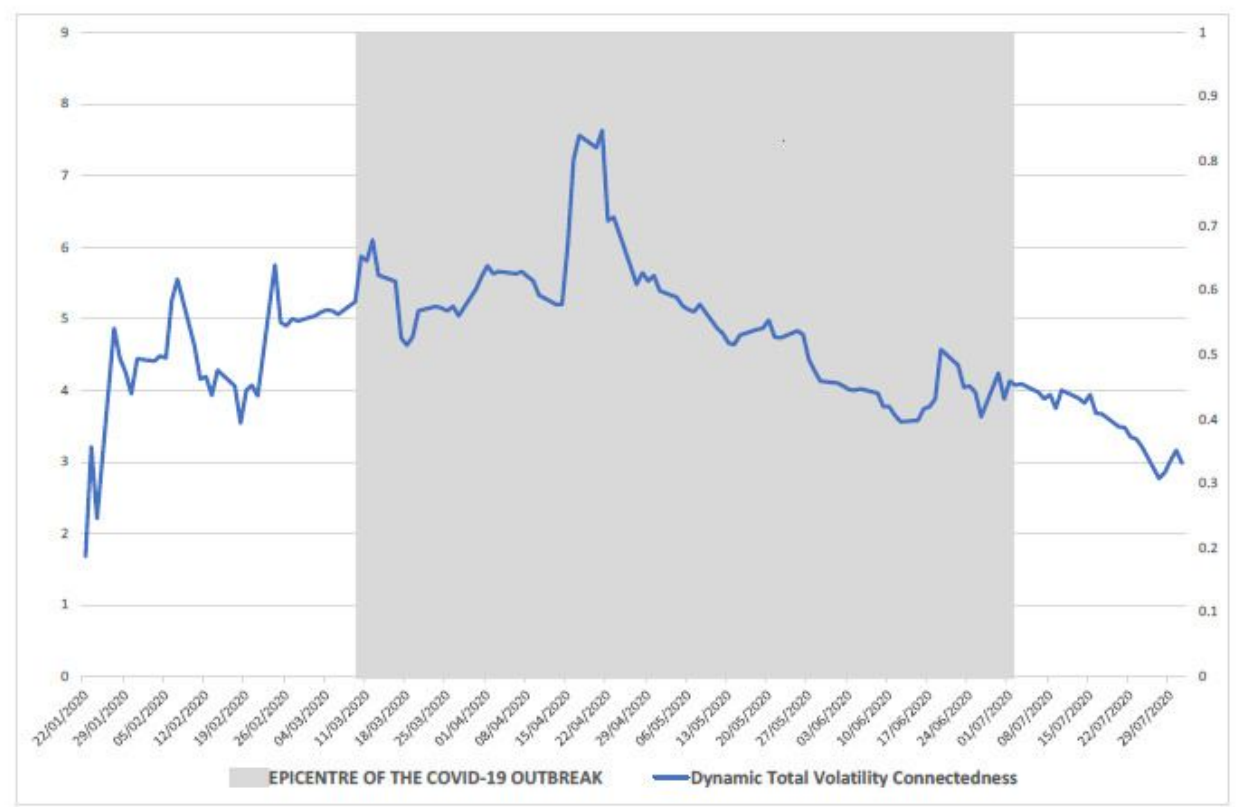

Notes: We study the return and volatility connectedness between the most relevant agricultural commodity markets (Softs, Grains and Livestock) and the Coronavirus MCI (Media Coverage Index) - obtained from RavenPack-, within the TVP-VAR framework (Antonakakis and Gabauer, 2017).

\section{Figure 4}

Dynamic total connectedness over time 


\section{Panel A: In returns}

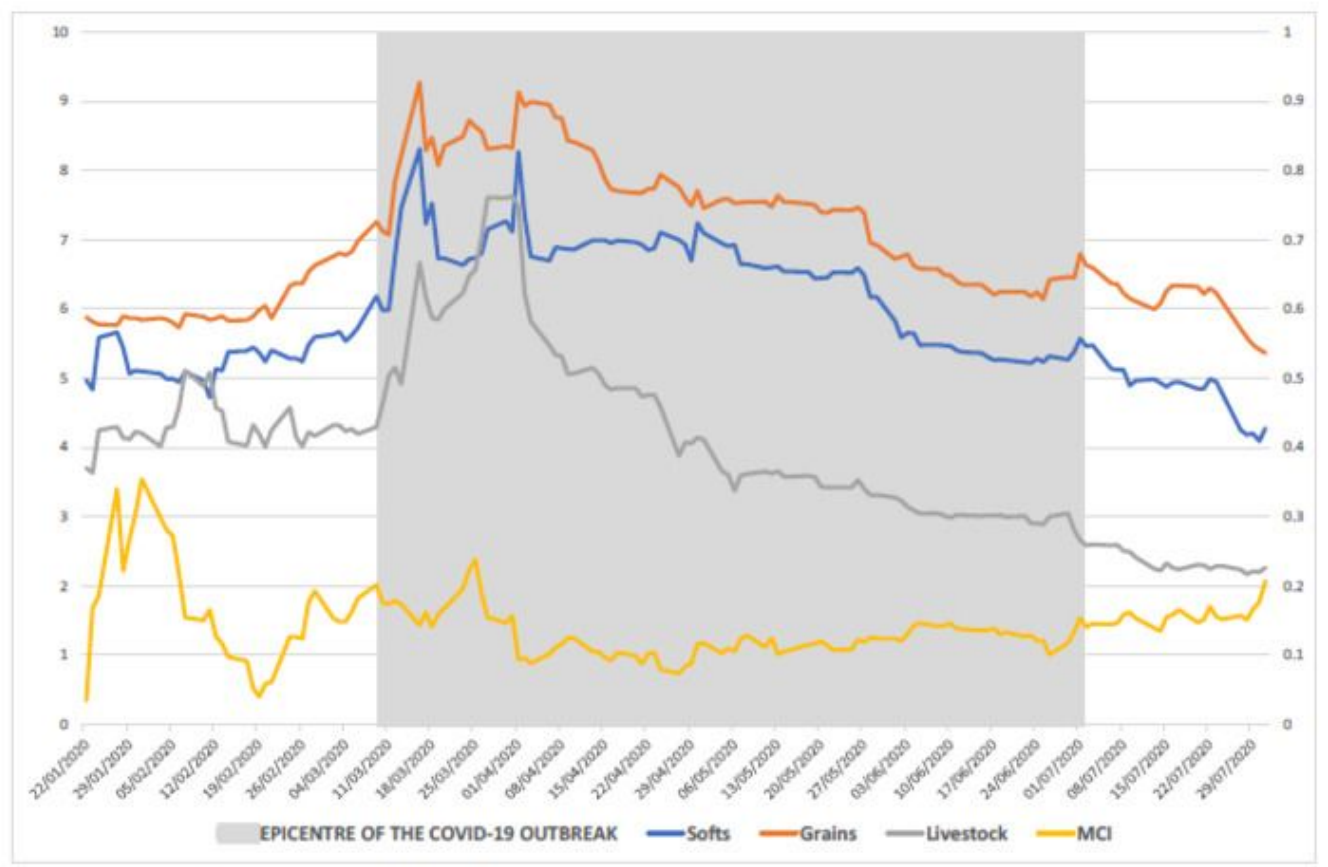

Panel B: In volatility

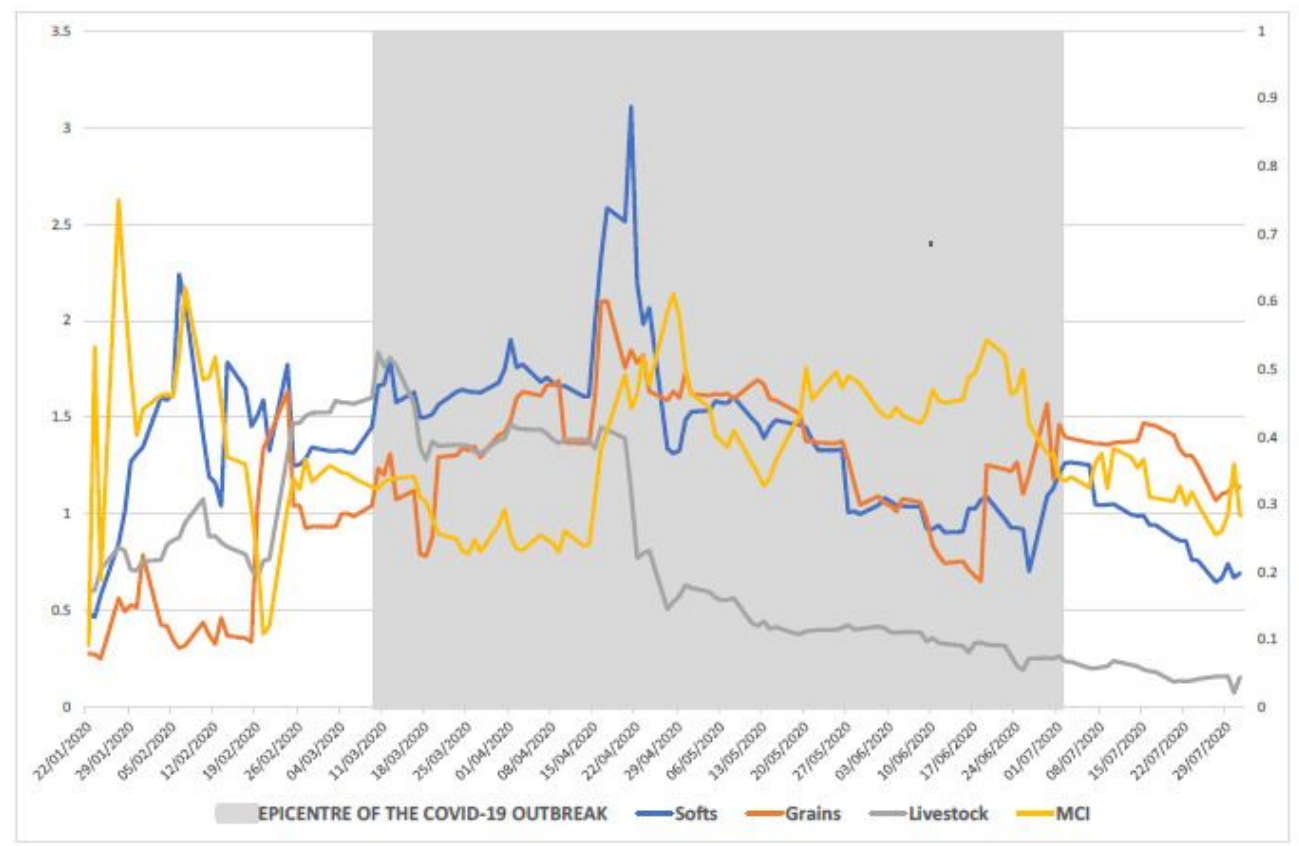

Notes: We study the return and volatility connectedness between the most relevant agricultural commodity markets (Softs, Grains and Livestock) and the Coronavirus MCI (Media Coverage Index) - obtained from RavenPack-, within the TVP-VAR framework (Antonakakis and Gabauer, 2017).

\section{Figure 5}

Dynamic contribution of the industrial metals TO the system 


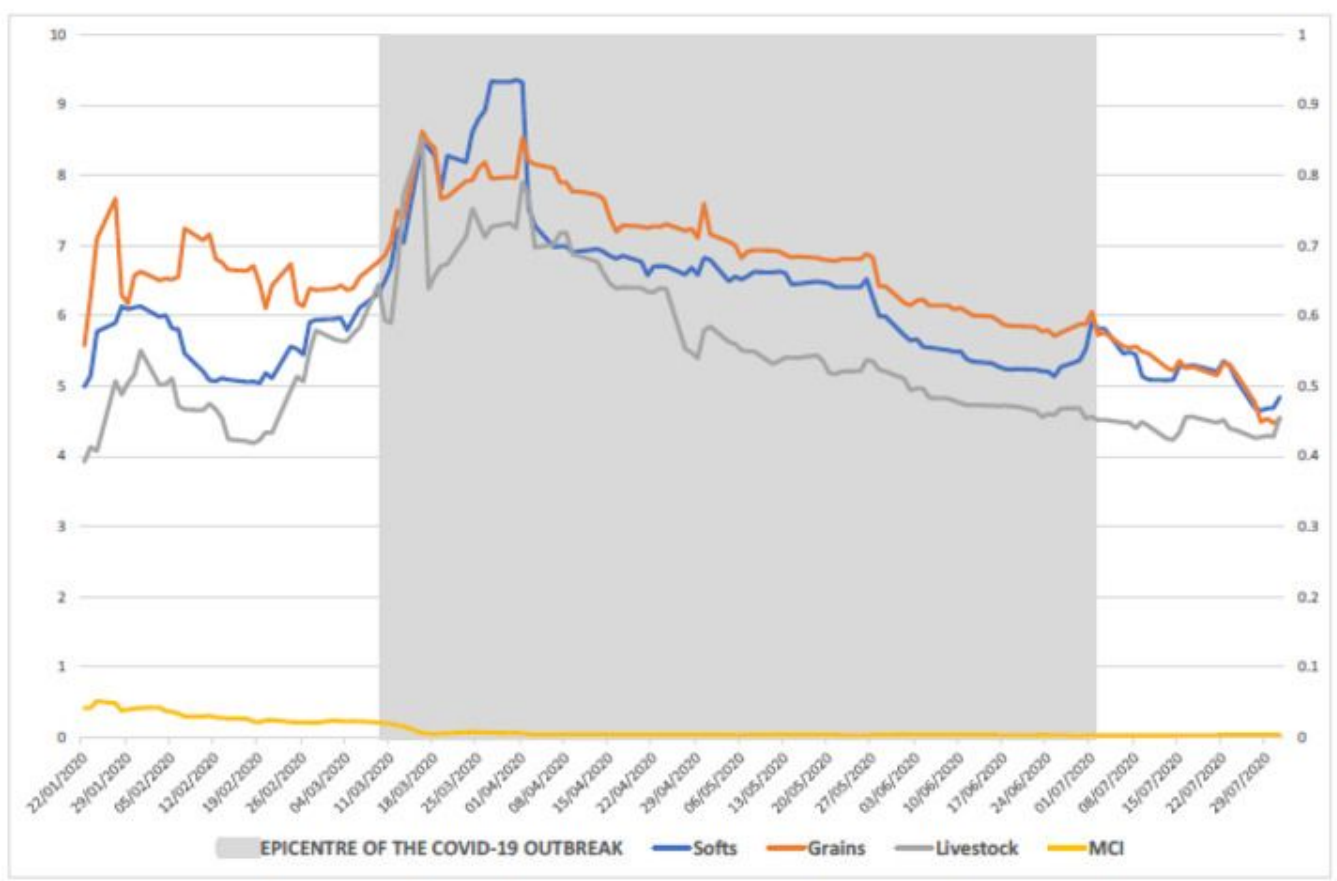

Panel B: In volatility

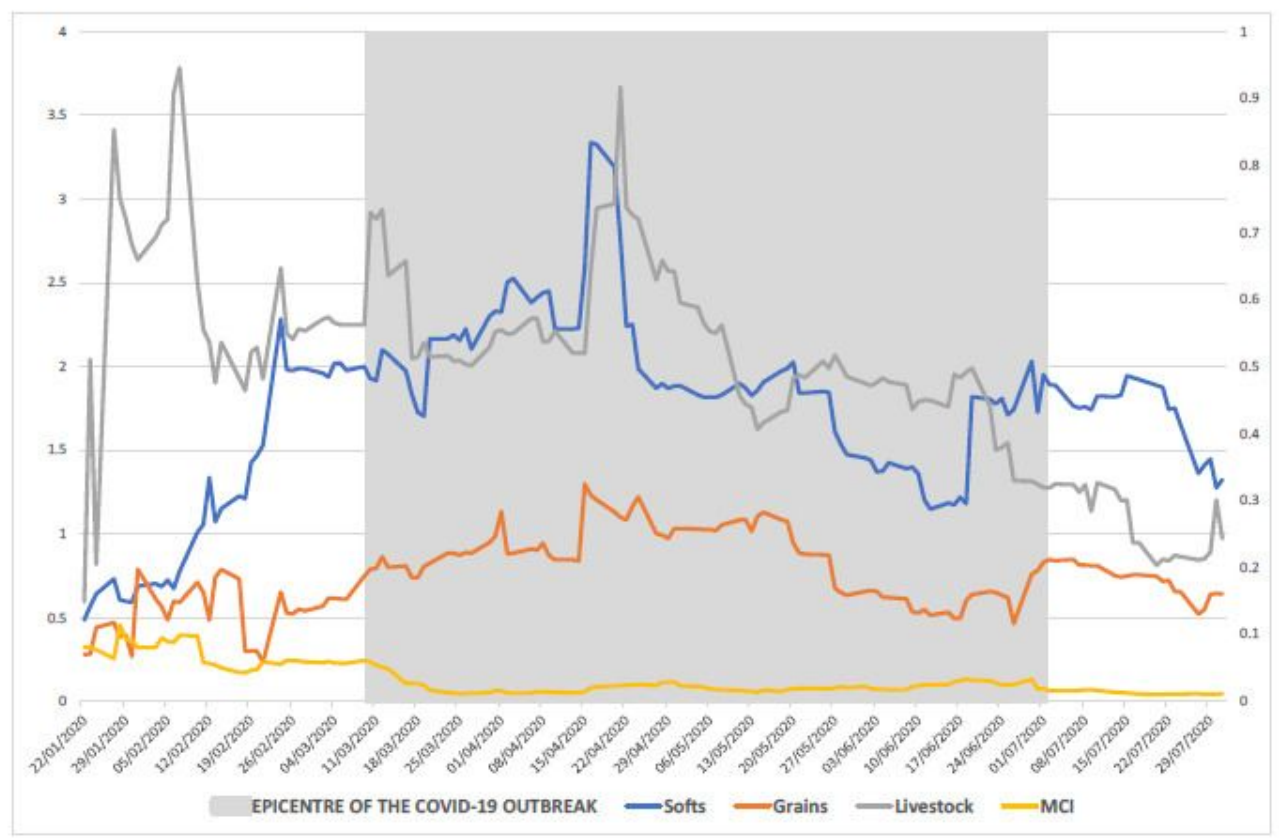

Notes: We study the return and volatility connectedness between the most relevant agricultural commodity markets (Softs, Grains and Livestock) and the Coronavirus MCI (Media Coverage Index) - obtained from RavenPack-, within the TVP-VAR framework (Antonakakis and Gabauer, 2017).

\section{Figure 6}

Dynamic contribution FROM the system to the industrial metals 


\section{Panel A: In returns}

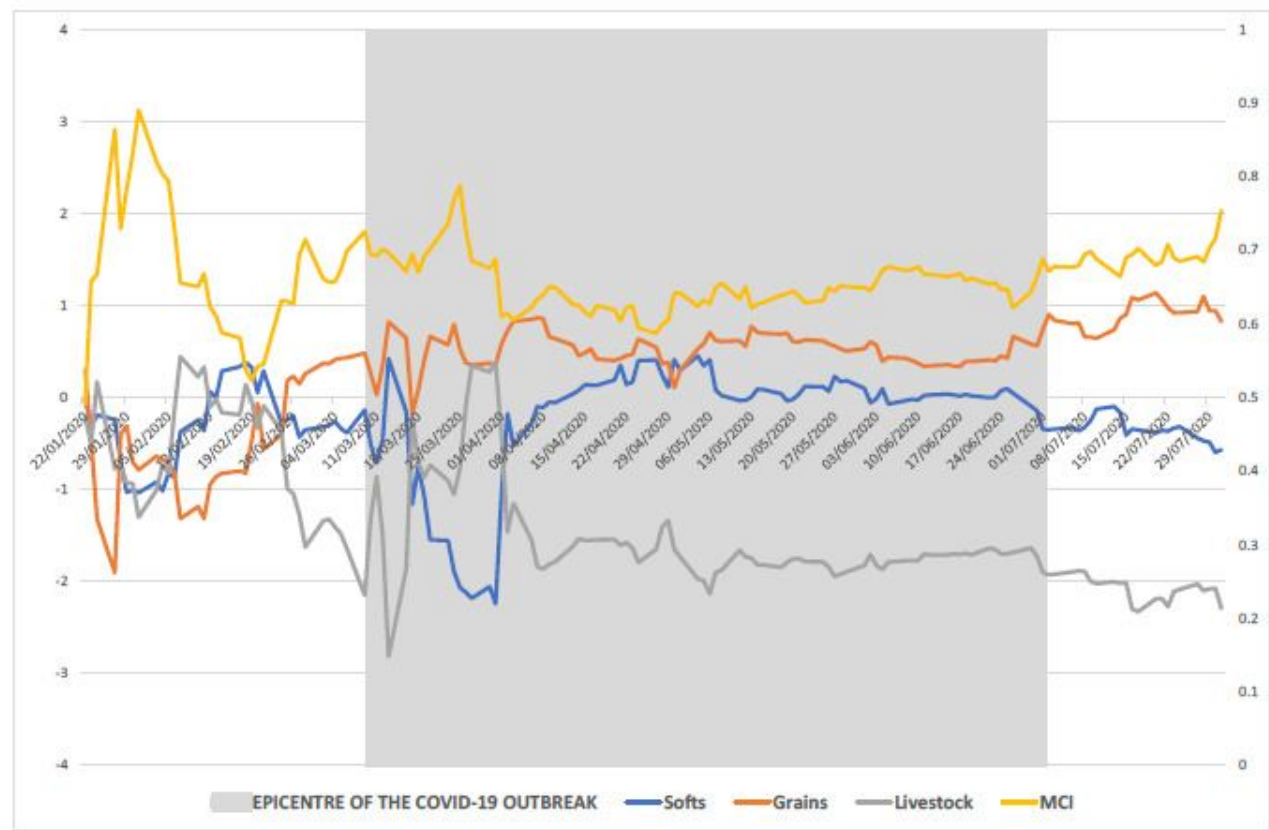

Panel B: In volatility

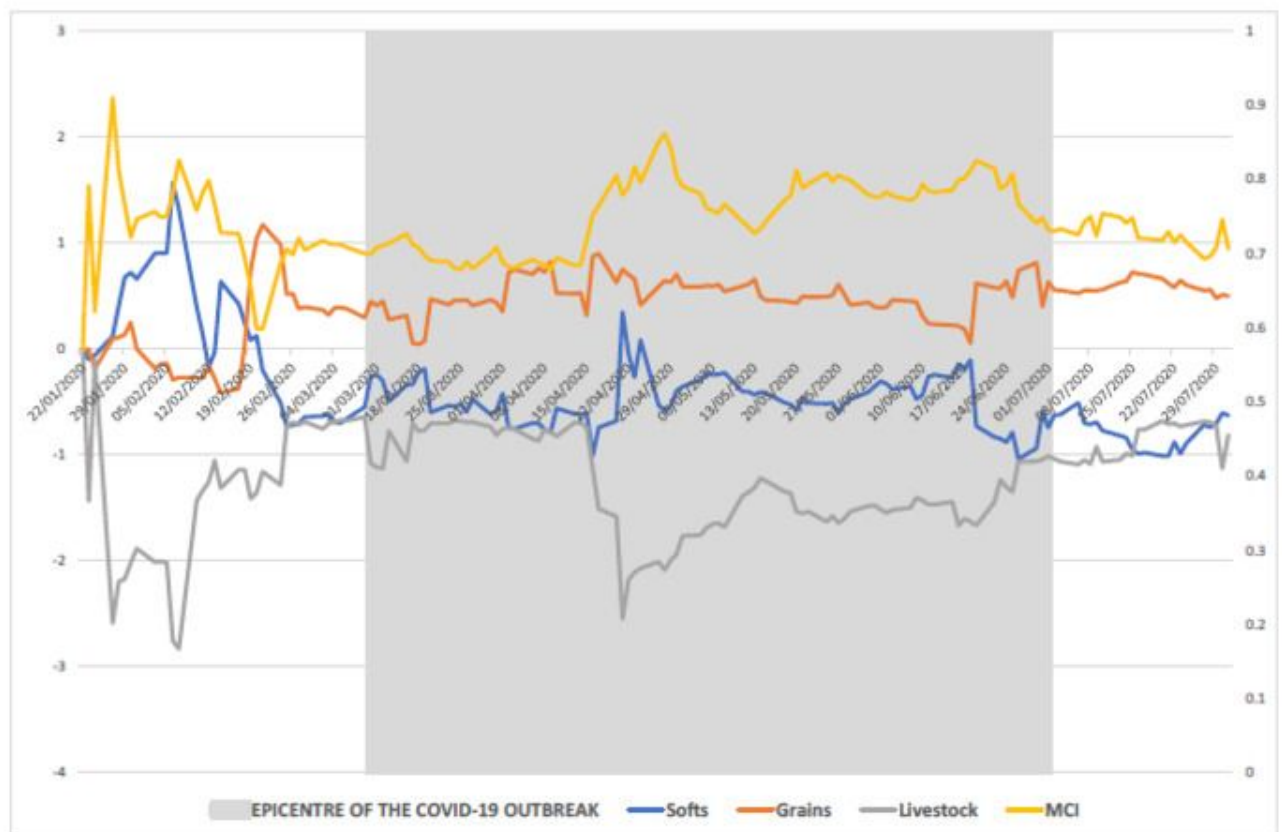

Notes: We study the return and volatility connectedness between the most relevant agricultural commodity markets (Softs, Grains and Livestock) and the Coronavirus MCI (Media Coverage Index) - obtained from RavenPack-, within the TVP-VAR framework (Antonakakis and Gabauer, 2017).

\section{Figure 7}

Net dynamic total connectedness 